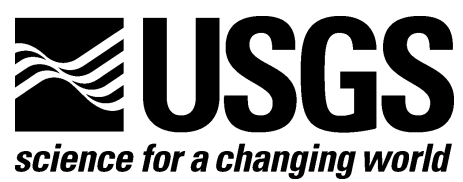

\title{
Location of the Green Canyon (Offshore Southern Louisiana) Seismic Event of February 10, 2006
}

By James W. Dewey and Joseph A. Dellinger

Open-File Report 2008-1184

U.S. Department of the Interior U.S. Geological Survey 


\section{U.S. Department of the Interior DIRK KEMPTHORNE, Secretary}

\section{U.S. Geological Survey Mark D. Myers, Director}

U.S. Geological Survey, Reston, Virginia: 2008

For product and ordering information:

World Wide Web: http://www.usgs.gov/pubprod

Telephone: 1-888-ASK-USGS

For more information on the USGS—the Federal source for science about the Earth, its natural and living resources, natural hazards, and the environment:

World Wide Web: http://www.usgs.gov

Telephone: 1-888-ASK-USGS

Suggested citation:

Dewey, J. W., and Dellinger, J.A., 2008, . Location of the Green Canyon Event (Offshore Southern Louisiana) of February 10, 2006, U. S. Geological Survey Open-File Report 2008-1184, $31 \mathrm{p}$.

Any use of trade, product, or firm names is for descriptive purposes only and does not imply endorsement by the U.S. Government.

Although this report is in the public domain, permission must be secured from the individual copyright owners to reproduce any copyrighted material contained within this report. 


\section{Contents}

Abstract

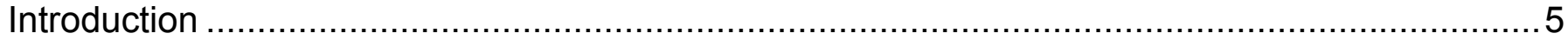

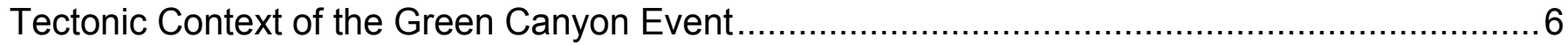

Preferred Hypocenter for the Green Canyon Event ....................................................... 8

Procedure and Arrival-Time Data Used to Calculate the Preferred Hypocenter for the

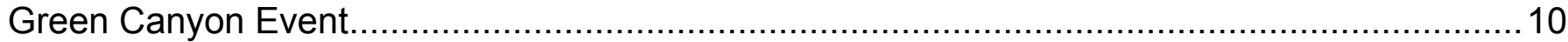

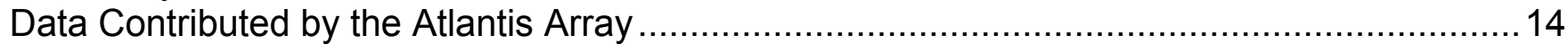

Data Contributed by the CGG Green Canyon Phase VIII Multi-Client Survey ........................19

Data Obtained from the Routinely Processed USGS/NEIC Data-Stream ..............................21

A Test of Other Approaches to Calculating the Epicenter of the Green Canyon Event from

Seismic Phase Arrival-Times .......................................................................................22

Constraints on the Epicenter of the Green Canyon Event from the Azimuth-of-Approach of

Seismic Waves Recorded by the Atlantis Array and the CGG Green Canyon Phase VIII

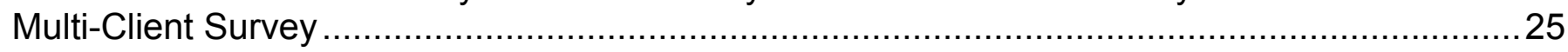

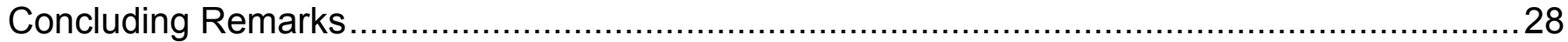

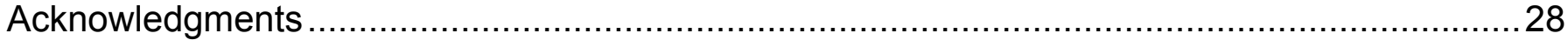

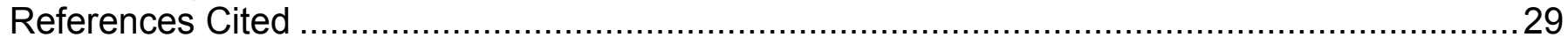

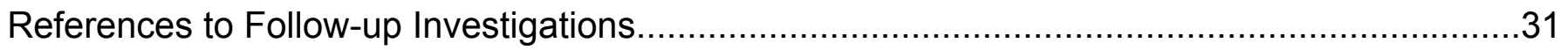

\section{Figures}

1. Location map of Green Canyon event, showing the preferred USGS/NEIC hypocenter with its associated $90 \%$ confidence ellipse and the previous USGS/NEIC hypocenter ..... 6

2. Graphs showing comparison of seismograms recorded at station JCT (Junction, Texas) from the Green Canyon event and from the Gulf of Mexico earthquake of May 23, 2007, which occurred offshore of the States of Tamaulipas and Veracruz, Mexico..... 8

3. Map showing preferred epicenter and associated $90 \%$ confidence ellipse for the Green Canyon event of February 10, 2006

4. Diagram showing vertical-component data from the Atlantis array, filtered, grouped into receiver arrays, and slant-stacked.

5. Diagram showing Atlantis array east-west component data that have been filtered, grouped into receiver arrays, and slant-stacked with an apparent velocity of 2,900m/s .. 17

6. Diagram showing Atlantis array vertical-component data that have been filtered, grouped into receiver arrays, and slant-stacked with an apparent velocity of 1,690 m/s . 18

7. Plots of three successive shots from the CGG Green Canyon phase VIII multi-client survey data stacked over the entire towed-streamer array ........................................... 20

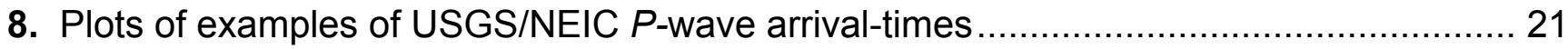

9. Map of epicenters calculated for the Green Canyon event using two different focal depths, different combinations of phase arrival times, and different arrival times ............ 23

10. Diagram showing $1,500 \mathrm{~km} / \mathrm{s}$ energy intensity recorded at the Atlantis array as a function of azimuth and time.... 26

11. Diagram showing $1,500 \mathrm{~km} / \mathrm{s}$ energy intensity recorded by the CGG Green Canyon phase VIII multi-client survey as a function of azimuth and time 


\section{Tables}

1. Preferred hypocenter for the Green Canyon event, calculated using USGS/NEIC data, data recorded by the Atlantis array, and data recorded during the CGG Green Canyon phase VIII multi-client survey.

2. Previous hypocenter for the Green Canyon event, calculated using only arrival-time data that are routinely read at, or contributed to, the USGS/NEIC

3. Arrival-time data considered for locating the Green Canyon event .............................. 12

4. Abbreviations and geographic coordinates of reference points of the Atlantis array groupings and of the CGG Green Canyon phase VIII multi-client survey

5. Velocity model that is used in a test to adjust the $P$-wave arrival-times for the effect of the Earth's crust and upper mantle beneath the Gulf of Mexico being different than the crust and upper mantle of the model of Herrin and others (1968). 


\title{
Location of the Green Canyon (Offshore Southern Louisiana) Seismic Event of February 10, 2006
}

\author{
By James W. Dewey ${ }^{1}$ and Joseph A. Dellinger ${ }^{2}$
}

\section{Abstract}

We calculated an epicenter for the Offshore Southern Louisiana seismic event of February 10, 2006 (the "Green Canyon event") that was adopted as the preferred epicenter for the event by the USGS/NEIC. The event is held at a focal depth of $5 \mathrm{~km}$; the focal depth could not be reliably calculated but was most likely between $1 \mathrm{~km}$ and $15 \mathrm{~km}$ beneath sea level. The epicenter was calculated with a radially symmetric global Earth model similar to that routinely used at the USGS/NEIC for all earthquakes worldwide. The location was calculated using $P$-waves recorded by seismographic stations from which the USGS/NEIC routinely obtains seismological data, plus data from two seismic exploration arrays, the Atlantis ocean-bottom node array, operated by BP in partnership with BHP Billiton Limited, and the CGG Green Canyon phase VIII multi-client towedstreamer survey. The preferred epicenter is approximately $26 \mathrm{~km}$ north of an epicenter earlier published by the USGS/NEIC, which was obtained without benefit of the seismic exploration arrays. We estimate that the preferred epicenter is accurate to within $15 \mathrm{~km}$.

We selected the preferred epicenter from a suite of trial calculations that attempted to fit arrival times of seismic energy associated with the Green Canyon event and that explored the effect of errors in the velocity model used to calculate the preferred epicenter. The various trials were helpful in confirming the approximate correctness of the preferred epicenter and in assessing the accuracy of the preferred epicenter, but none of the trial calculations, including that of the preferred epicenter, was able to reconcile arrival-time observations and assumed velocity model as well as is typical for the vast majority of earthquakes in and near the continental United States. We believe that remaining misfits between the preferred solution and the observations reflect errors in interpreted arrival times of emergent seismic phases that are due partly to a temporally extended source-time function and partly to failure of our travel-time model to account for the extremely complicated velocity structure of the sedimentary section in which the event occurred.

\section{Introduction}

The purpose of this report is to describe the procedure and data used to calculate the preferred U.S. Geological Survey National Earthquake Information Center (USGS/NEIC) origin for the "Green Canyon" (offshore southern Louisiana) seismic event of February 10, 2006 ( $m_{b}$ magnitude 4.2, $M_{S}$ magnitude 5.3). The preferred solution is based partly on seismic phase arrival-

\footnotetext{
${ }^{1}$ U.S. Geological Survey, MS 966, Denver, CO 80225.

${ }^{2}$ BP, 501 Westlake Park Blvd., Houston, TX 77079.
} 
time data that were interpreted at, or contributed to, the USGS/NEIC office in Golden, Colorado, and the solution is based partly on data obtained from seismic instrumentation that was recording in the Gulf of Mexico for the purpose of petroleum exploration. The latter data are of a type not normally used by the USGS/NEIC in its earthquake location procedures; these data were acquired by the second author of this report.

The offshore southern Louisiana seismic event has attracted much interest in the U.S. Gulf Coast energy industry, because of its location in an area of dense infrastructure associated with the production of petroleum (fig. 1). The event was felt onboard one offshore production platform (Rijken and Leverette, 2007) and at scattered locations along the U.S. Gulf Coast (U.S. Geological Survey, 2008). The nomenclature "Green Canyon event" is commonly applied to the earthquake by those in the energy industry, and we retain the nomenclature in this report.

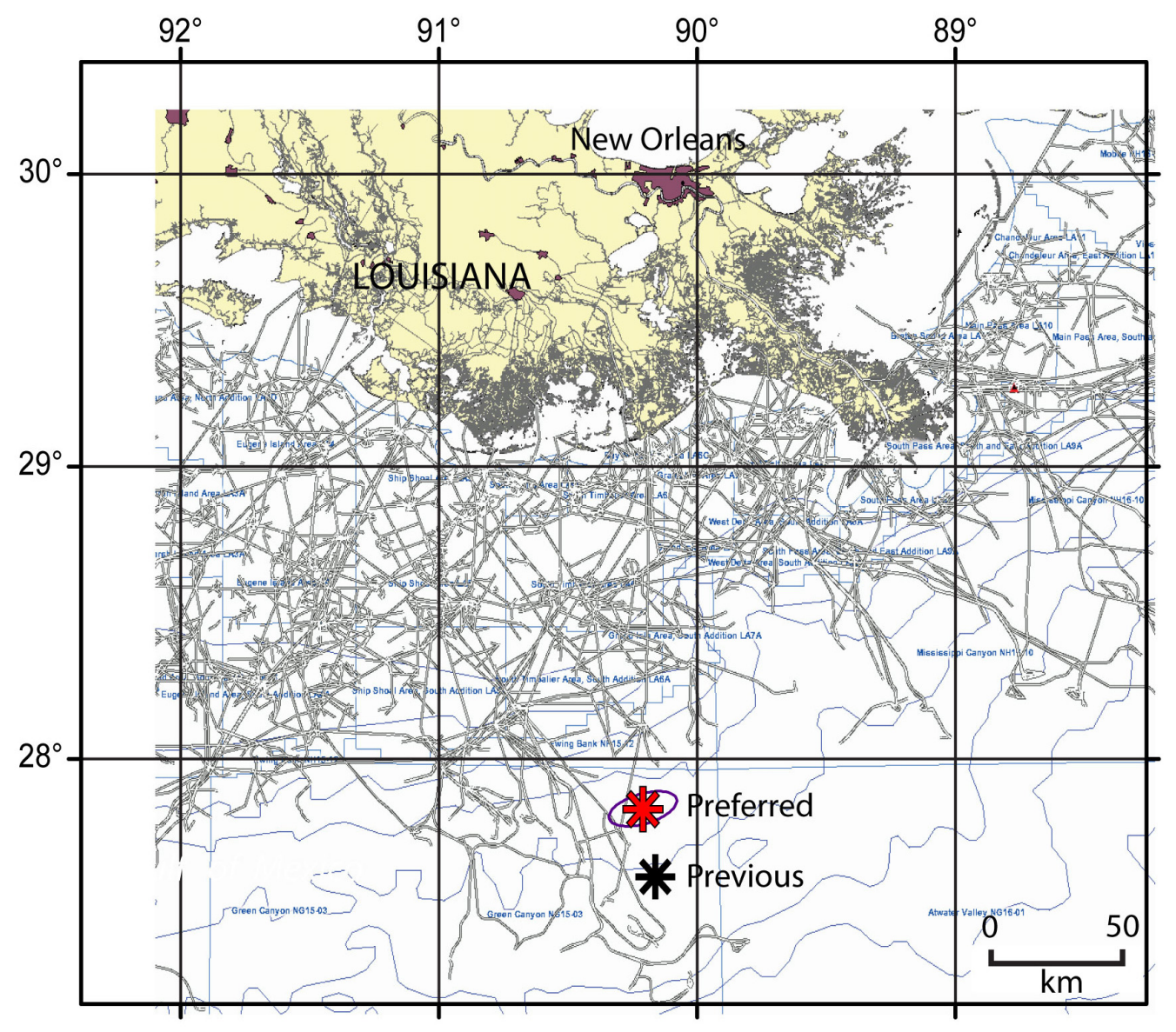

Figure 1. Location map of Green Canyon event, showing the preferred USGS/NEIC hypocenter with its associated $90 \%$ confidence ellipse and the previous USGS/NEIC hypocenter. Gray lines offshore represent energy pipelines. The pipeline and geography image was downloaded from the Minerals Management Service (2008).

\section{Tectonic Context of the Green Canyon Event}

The Green Canyon event of February 10, 2006, occurred within a broad region that has historically had a low, but non-null, level of earthquake activity (Frohlich, 1982; Nunn, 1985; 
Dokka and others, 2006). Several mechanisms had been proposed for Gulf of Mexico seismicity prior to the occurrence of the Green Canyon event (see studies cited in previous paragraph), and a mechanism not previously proposed for Gulf of Mexico shocks has been proposed specifically for the Green Canyon event (Nettles, 2006, 2007). Although the purpose of this report is not to arrive at a definite conclusion or "preferred speculation" on the cause of the Green Canyon event, calculation of the event's hypocenter requires interpretation of the seismic waves generated by the event, and this in turn requires some consideration of the ultimate cause of the earthquake. We consider three general causative mechanisms for a seismic event in the region offshore of southern Louisiana, starting from the most deep-seated mechanism and working toward the surface of the Earth's crust beneath the ocean. First, an arbitrary seismic event in the Gulf of Mexico might represent faulting within crystalline basement beneath the approximately 13-km thick sedimentary section (Frohlich, 1982; Nunn, 1985). Second, an arbitrary seismic event in the offshore Louisiana region of the Gulf of Mexico might represent faulting within the sedimentary section (Kovach, 1974; Ottemöller and others, 2005; Dokka and others, 2006). Third, an arbitrary seismic event in the offshore Louisiana region might represent slumping or a landslide within the sedimentary section (Richter, 1958, p. 155-156; Nettles, 2006, 2007).

From the broad characteristics of the seismic waveforms generated by the Green Canyon earthquake, we consider a source within the crystalline basement most unlikely for this specific event and thus favor the second or third mechanisms discussed in the previous paragraph. From both observational and theoretical perspectives (for example, McGarr, 1984), we expect that fracture of crystalline basement beneath the 13-km thick sedimentary section, with a focal depth of $15 \mathrm{~km}$ or more beneath sea level, would generate an impulsive signal with substantial highfrequency seismic energy. The Green Canyon event, however, was characterized by a deficiency of high-frequency energy, relative to the amount of low-frequency energy produced. Figure 2 compares a seismogram of the Green Canyon event with a seismogram from another Gulf of Mexico earthquake that probably did occur in crystalline basement, the offshore Mexico earthquake of May 23, 2007 (19:09:15.1 UTC, $m_{b}$ magnitude 5.4, $M_{S}$ magnitude 4.8). The seismogram of the offshore Mexico earthquake is more typical of what one would expect with a moderate-sized earthquake occurring in a midplate tectonic environment at mid-crustal or lower-crustal depths. The Green Canyon event's relatively low production of high-frequency energy is also reflected in the event's low $m_{b}$ magnitude (a measure of high-frequency energy) with respect to the event's $M_{s}$ magnitude (a measure of low-frequency energy). Based on $m_{b}$ versus $M_{s}$ values for earthquakes occurring around the world, one would expect that an $M_{s} 5.3$ earthquake would have an $m_{b}$ of 5.4 or larger (see, for example, Stevens and Day, 1985). The observed value of $m_{b} 4.2$ for the $M_{s} 5.3$ Green Canyon event is very inconsistent with observations of earthquakes occurring in highly competent rock. For the rest of our analysis, we will assume that the Green Canyon event occurred within the sedimentary section. Preliminarily, it appears to us that the small amount of highfrequency energy implied for the Green Canyon event by its $m_{b}$ value is consistent with either faulting at shallow depths within the sedimentary section or a large landslide. Inefficient generation of high-frequency energy would be expected for faulting of weak sedimentary rock at shallow depths in the Earth's crust (Kovach, 1974; Ottemöller and others, 2005). Inefficient generation of high-frequency energy and strong generation of long-period energy is also expected for a submarine landslide source (for example, Richter, 1958, p. 155-156). 

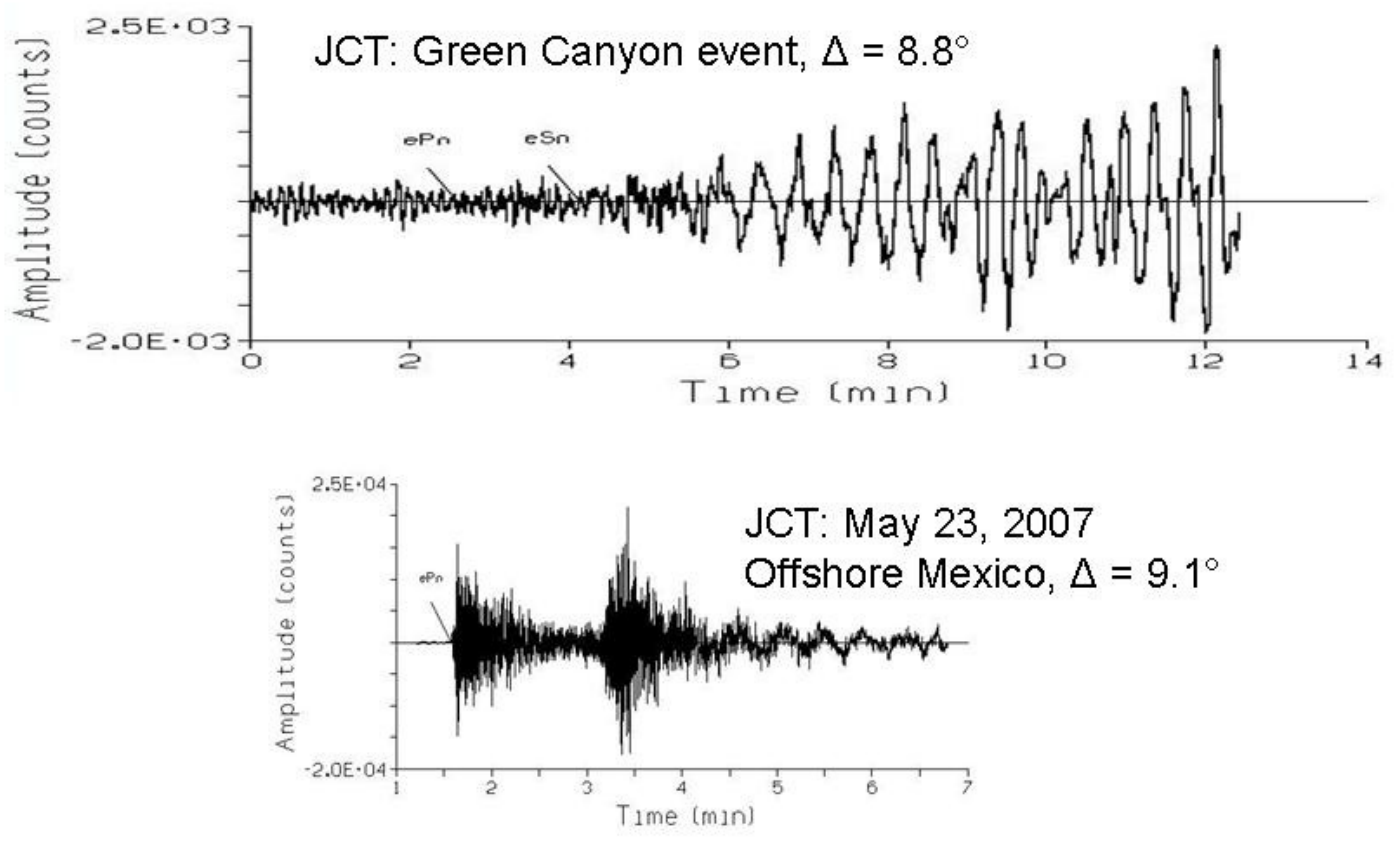

Figure 2. Comparison of seismograms recorded at station JCT (Junction, Texas) from the Green Canyon event and from the Gulf of Mexico earthquake of May 23, 2007, which occurred offshore of the States of Tamaulipas and Veracruz, Mexico. The time scales are approximately the same; the amplitude for the Green Canyon event is exaggerated about 10 times with respect to the Offshore Mexico earthquake. Station JCT is located at approximately the same distance from both events, and the two signals are both unfiltered output from the same velocity-proportional broadband seismometer.

\section{Preferred Hypocenter for the Green Canyon Event}

For the hypocenter of the Green Canyon event, the USGS/NEIC has adopted the hypocenter of table 1 and figure 3 .

Table 1. Preferred hypocenter for the Green Canyon event, calculated using USGS/NEIC data, data recorded by the Atlantis array and data recorded during the CGG Green Canyon phase VIII multi-client survey.

\begin{tabular}{ccccc}
\hline Date & Origin-time & Latitude N. & Longitude W. & $\begin{array}{c}\text { Depth } \\
\mathbf{k m}\end{array}$ \\
\hline 20060210 & 041422.2 & 27.828 & 90.210 & $\begin{array}{c}5.0 \text { (restrained by } \\
\text { geophysicist) }\end{array}$ \\
\hline
\end{tabular}

We restrained the focal depth to $5 \mathrm{~km}$ because the arrival-time data did not allow a reliable depth computation. Given the distance of recording stations from the epicenter, reliable 
determination of a focal depth within the upper crust would require the explicit identification within the recorded signal of seismic phases that have been reflected off the Earth's surface, but the seismic signature of the Green Canyon event is too complex to allow the identification of such phases. As discussed in the previous section, the event almost certainly occurred in the sedimentary section of the upper crust (between about 1 and $15 \mathrm{~km}$ below sea level in the region of the epicenter), and a causative mechanism involving faulting of weak rocks or landsliding favors a location in the uppermost several kilometers.

The USGS/NEIC describes the source of the calculated hypocenter as "SPEC," signifying that it is an NEIC solution based on a local velocity model or other special methods. The hypocenter is electronically published in the USGS/NEIC Preliminary Determination of Epicenters monthly bulletin for February 2006 and available on-line at "ftp://hazards.cr.usgs.gov/pde/manuscript/mon200602.lis". A listing of the hypocenter accompanied by station phase arrival-time and amplitude data is provided at "ftp://hazards.cr.usgs.gov/edr/mchedr/".

The epicenter of table 1 supersedes an earlier estimate for the epicenter of the Green Canyon event that was published in the USGS/NEIC Preliminary Determination of Epicenters weekly bulletin for the sixth week of 2006. The earlier epicenter is given in table 2 and plotted in figure 3. The earlier hypocenter was electronically available on-line at "ftp://hazards.cr.usgs.gov/weekly/." As is the case for all weekly bulletins, the weekly bulletin for the sixth week of 2006 was deleted from the USGS/NEIC website with publication of the monthly bulletin that covers the same time-period.

Table 2. Previous hypocenter for the Green Canyon event, calculated using only arrival-time data that are routinely read at, or contributed to, the USGS/NEIC.

\begin{tabular}{ccccc}
\hline Date & Origin-time & Latitude N. & Longitude W. & $\begin{array}{c}\text { Depth } \\
\mathbf{k m}\end{array}$ \\
\hline 20060210 & 041417.8 & 27.597 & -90.163 & $\begin{array}{c}5.0 \text { (restrained by } \\
\text { geophysicist) }\end{array}$ \\
\hline
\end{tabular}

A formal estimate of the uncertainty of the epicenter is provided by the $90 \%$ confidence ellipse on epicentral coordinates (fig. 3). If all of the statistical assumptions used in the location of the earthquake were correct, the true epicenter of the Green Canyon event would have a $90 \%$ probability of being situated within an ellipse that is centered on the calculated epicenter and that has a major axis oriented N. $74^{\circ}$ E., semi-length $13.4 \mathrm{~km}$, and a perpendicular minor axis having a semi-length of $5.7 \mathrm{~km}$ (Evernden, 1969). The formal uncertainty would suggest that the position of the epicenter is most uncertain in the ENE-WSW directions. However, the formal uncertainty only accounts for the distribution of seismographic stations with respect to the epicenter and for Gaussian noise in the arrival-time data. The formal uncertainty does not account for systematic errors in the velocity model that is used to locate the earthquake, and it does not account for departures from the Gaussian error model, such as would arise if large observational errors were more frequent than predicted by the Gaussian error model. As a result, the formal $90 \%$ confidence ellipse probably underestimates the actual uncertainty of the preferred epicenter. As discussed below (section entitled, "A test of other approaches to calculating the epicenter of the Green Canyon event from seismic phase arrival-times"), exploration of different assumptions about the velocity model suggests higher uncertainty in the north-northwest/south-southeast directions than is indicated by the formal confidence ellipse. We think that uncertainty in the epicenter should be considered about $+/-15 \mathrm{~km}$ in any azimuth, at a $90 \%$ level of confidence: this is a "best judgment" estimate of author Dewey, based on both the formal confidence ellipse and the exploration of other approaches to locating the epicenter. 


\section{Procedure and Arrival-Time Data Used to Calculate the Preferred Hypocenter for the Green Canyon Event}

We calculated the preferred hypocenter using a single-event hypocenter location program written by Dewey (1971). The computational methodology is based on the same principles as the methodology used to routinely locate earthquakes at the USGS/NEIC, but we use the program of Dewey in order to have greater flexibility in the use of data from non standard sources and in order to explore the use of data-types that cannot currently be used in the USGS/NEIC procedure.

We used the travel-time tables of Herrin and others (1968) to obtain the theoretical travel times used in the earthquake location procedure. The Herrin and others (1968) travel-time tables are based on a radially symmetric model of the Earth's velocity, with an upper-crustal $P$-wave velocity of $6.0 \mathrm{~km} / \mathrm{s}$, a mid-crustal $P$-wave velocity of $6.75 \mathrm{~km} / \mathrm{s}$, and an upper-mantle $P$-wave velocity of $8.05 \mathrm{~km} / \mathrm{s}$ encountered at a depth of $40 \mathrm{~km}$. In reality, the travel times from the Green Canyon event to recording seismographic stations are not likely to be particularly well described by the model of Herrin and others (1968) or by any other radially symmetric global velocity model. It is not unusual for the use of inappropriate velocity models to lead to location bias of more than 10 $\mathrm{km}$ for shocks, such as the Green Canyon event, that are located with teleseismic data, and bias of more than $25 \mathrm{~km}$ has been reported even for widely recorded events (for example, Engdahl and others, 1998). In the section entitled, "A test of other approaches to calculating the epicenter of the Green Canyon event from seismic phase arrival-times," we report on epicenter computations that are based on a more realistic model for near-source velocity structure. In the end, however, we could not find an approach that would not yield some contradictions with available data, and the epicenter calculated with the model of Herrin and others (1968) has the virtue of being simple to describe, similar to the epicenter that would have been calculated with routine USGS/NEIC methodology, and near the middle of the cloud of epicenters calculated with other model assumptions.

Our preferred location for the Green Canyon event was calculated using $P$-wave arrival times obtained from the regular network of seismometers that transmit data to the USGS/NEIC office, plus $P$-wave arrival times obtained from an underwater seismic array, the Atlantis oceanbottom node array, operated by BP in partnership with BHP Billiton Limited, plus a $P$-wave arrival time interpreted from the CGG Green Canyon phase VIII multi-client towed-streamer survey. For the purposes of weighting observations, we assumed that arrival-time observations from the Atlantis array and the CGG Green Canyon phase VIII multi-client survey have a population variance of $1 \mathrm{sec}^{2}$ and that arrival-time observations from the USGS/NEIC stations have a population variance of $10 \mathrm{sec}^{2}$; because weights are inversely proportional to variance, the Atlantis and CGG Green Canyon phase VIII data are therefore more heavily weighted than the USGS/NEIC data.

Stations that were used in the location process are listed in table 3. Geographic coordinates of the standard stations used by the USGS/NEIC are available on-line (U.S. Geological Survey, 2007). Coordinates used for observations from the Atlantis array and the CGG Green Canyon phase VIII multi-client survey are given in table 4. 


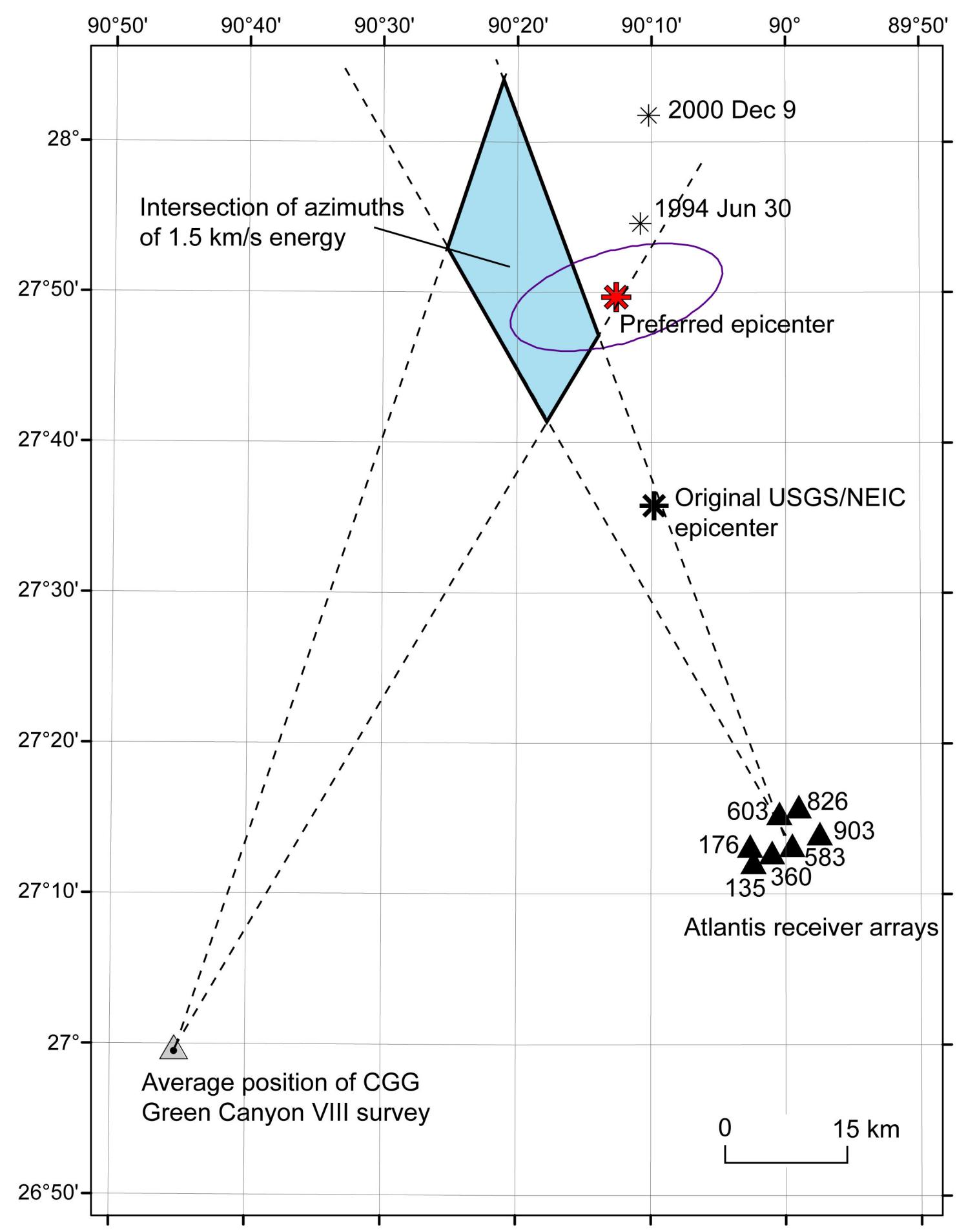

Figure 3. Preferred epicenter and associated $90 \%$ confidence ellipse for the Green Canyon event of February 10, 2006. Dashed lines indicate the azimuths-of-approach of energy recorded at the Atlantis array and the CGG Green Canyon phase VIII multi-client survey and having an apparent velocity of $1.5 \mathrm{~km} / \mathrm{s}$; their inclusion in this figure anticipates discussion of figures 10 and 11 . Epicenters of two earlier earthquakes and the original USGS/NEIC epicenter of the Green Canyon event are also shown. Atlantis receiver arrays used in figures 4, 5, and 6 are labeled. 
Table 3. Arrival-time data considered for locating the Green Canyon event.

\begin{tabular}{|c|c|c|c|c|c|c|c|}
\hline Station & Quality & Phase & Distance $\left({ }^{\circ}\right)$ & Azimuth $\left({ }^{\circ}\right)$ & Arrival time(s) & Residual(s) & Model \\
\hline AA603* & & $\mathrm{P}$ & 0.6 & 162.48 & 11.2 & 0.17 & Herrin(1968) \\
\hline AA603* & & UG2 & 0.6 & 162.48 & 47.8 & 8.52 & $1.69 \mathrm{~km} / \mathrm{s}$ \\
\hline AA826* & & $\mathrm{P}$ & 0.6 & 160.3 & 11.1 & 0.07 & Herrin(1968) \\
\hline AA826* & & UG2 & 0.6 & 160.3 & 47.8 & 8.52 & $1.69 \mathrm{~km} / \mathrm{s}$ \\
\hline AA176* & & $\mathrm{P}$ & 0.62 & 166.28 & 11.5 & -0.01 & Herrin(1968) \\
\hline AA176* & & UG1 & 0.62 & 166.28 & 29.5 & 5.59 & $2.9 \mathrm{~km} / \mathrm{s}$ \\
\hline AA176* & & UG2 & 0.62 & 166.28 & 48.8 & 7.77 & $1.69 \mathrm{~km} / \mathrm{s}$ \\
\hline AA903* & & $\mathrm{P}$ & 0.63 & 159.21 & 12 & 0.33 & Herrin(1968) \\
\hline AA903* & & UG1 & 0.63 & 159.21 & 30.3 & 6.04 & $2.9 \mathrm{~km} / \mathrm{s}$ \\
\hline AA903* & & UG2 & 0.63 & 159.21 & 49.8 & 8.17 & $1.69 \mathrm{~km} / \mathrm{s}$ \\
\hline AA135* & & $\mathrm{P}$ & 0.64 & 166.32 & 11.8 & -0.02 & Herrin(1968) \\
\hline AA135* & & UG1 & 0.64 & 166.32 & 29.8 & 5.21 & $2.9 \mathrm{~km} / \mathrm{s}$ \\
\hline AA135* & & UG2 & 0.64 & 166.32 & 49.8 & 7.6 & $1.69 \mathrm{~km} / \mathrm{s}$ \\
\hline AA360* & & $\mathrm{P}$ & 0.64 & 164.29 & 11.8 & 0.08 & Herrin(1968) \\
\hline AA $360 *$ & & UG1 & 0.64 & 164.29 & 29.8 & 5.42 & $2.9 \mathrm{~km} / \mathrm{s}$ \\
\hline AA360* & & UG2 & 0.64 & 164.29 & 49.8 & 7.97 & $1.69 \mathrm{~km} / \mathrm{s}$ \\
\hline AA583* & & $\mathrm{P}$ & 0.64 & 162.18 & 11.9 & 0.18 & Herrin(1968) \\
\hline AA583* & & UG1 & 0.64 & 162.18 & 29.8 & 5.43 & $2.9 \mathrm{~km} / \mathrm{s}$ \\
\hline AA583* & & UG2 & 0.64 & 162.18 & 49.8 & 7.99 & $1.69 \mathrm{~km} / \mathrm{s}$ \\
\hline CGG-GC* & & $\mathrm{P}$ & 0.96 & 210.48 & 17.3 & -0.21 & Herrin(1968) \\
\hline CGG-GC* & & UG3 & 0.96 & 210.48 & 75.8 & 4.63 & $1.5 \mathrm{~km} / \mathrm{s}$ \\
\hline HKT & & $\mathrm{P}$ & 5.36 & 294.54 & 77.82 & -2.6 & Herrin(1968) \\
\hline NATX & $\mathrm{Q}$ & $\mathrm{P}$ & 5.51 & 316.44 & 78.84 & -3.5 & Herrin(1968) \\
\hline LRAL & & $\mathrm{P}$ & 5.88 & 27.33 & 87.29 & -0.23 & Herrin(1968) \\
\hline OXF & & $\mathrm{P}$ & 6.7 & 5.68 & 98.44 & -0.2 & Herrin(1968) \\
\hline UALR & Q & $\mathrm{P}$ & 7.16 & 345.77 & 108.28 & 3.3 & Herrin(1968) \\
\hline MIAR & $\mathrm{Q}$ & $\mathrm{P}$ & 7.29 & 337.54 & 105.23 & -1.5 & Herrin(1968) \\
\hline PLAL & & $\mathrm{P}$ & 7.36 & 13.81 & 108.04 & 0.34 & Herrin(1968) \\
\hline HBAR & Q & $\mathrm{P}$ & 7.71 & 357.28 & 111.64 & -0.86 & Herrin(1968) \\
\hline DWPF & & $\mathrm{P}$ & 7.77 & 85.88 & 107.16 & -6.08 & Herrin(1968) \\
\hline TEIG & Q & $\mathrm{P}$ & 7.77 & 166.45 & 106.54 & -6.75 & Herrin(1968) \\
\hline WVT & Q & $\mathrm{P}$ & 8.52 & 13.12 & 122.89 & -0.61 & Herrin(1968) \\
\hline JCT & & $\mathrm{P}$ & 8.79 & 289.77 & 124.23 & -2.98 & Herrin(1968) \\
\hline
\end{tabular}


Table 3. Continued.

\begin{tabular}{|c|c|c|c|c|c|c|c|}
\hline Station & Quality & Phase & Distance $\left({ }^{\circ}\right)$ & Azimuth $\left({ }^{\circ}\right)$ & Arrival time(s) & Residual(s) & Model \\
\hline MYNC & & $\mathrm{P}$ & 8.89 & 34.2 & 130.05 & 1.45 & Herrin(1968) \\
\hline WMOK & Q & $\mathrm{P}$ & 10.06 & 315.34 & 144.47 & 0.03 & Herrin(1968) \\
\hline FVM & $\mathrm{Q}$ & $\mathrm{P}$ & 10.13 & 359.03 & 143.12 & -2.29 & Herrin(1968) \\
\hline TZTN & & $\mathrm{P}$ & 10.36 & 31.3 & 148.45 & -0.05 & Herrin(1968) \\
\hline SLM & Q & $\mathrm{P}$ & 10.78 & 359.89 & 151.41 & -2.81 & Herrin(1968) \\
\hline WCI & $\mathrm{Q}$ & $\mathrm{P}$ & 10.88 & 16.56 & 155.62 & 0.05 & Herrin(1968) \\
\hline BLO & Q & $\mathrm{P}$ & 11.72 & 14.25 & 175.18 & 8.19 & Herrin(1968) \\
\hline KSU1 & Q & $\mathrm{P}$ & 12.44 & 336.26 & 169.01 & -7.69 & Herrin(1968) \\
\hline CBKS & Q & $\mathrm{P}$ & 13.53 & 326.46 & 191.33 & -0.07 & Herrin(1968) \\
\hline ANMO & & $\mathrm{P}$ & 15.58 & 301.13 & 219.62 & 1.08 & Herrin(1968) \\
\hline SDCO & Q & $\mathrm{P}$ & 16.2 & 311.47 & 227.24 & 0.65 & Herrin(1968) \\
\hline ISCO & & $\mathrm{P}$ & 17.47 & 317.04 & 243.3 & 0.62 & Herrin(1968) \\
\hline TUC & & $\mathrm{P}$ & 18.35 & 289.08 & 253.56 & 0.06 & Herrin(1968) \\
\hline WUAZ & Q & $\mathrm{P}$ & 19.55 & 298.35 & 264.04 & -3.53 & Herrin(1968) \\
\hline RSSD & Q & $\mathrm{P}$ & 19.69 & 329.28 & 279.2 & 10.09 & Herrin(1968) \\
\hline PDAR & & $\mathrm{P}$ & 21.64 & 318.58 & 294.06 & 3.58 & Herrin(1968) \\
\hline HWUT & $\mathrm{Q}$ & $\mathrm{P}$ & 22.22 & 313.76 & 302.88 & 6.39 & Herrin(1968) \\
\hline ULM & & $\mathrm{P}$ & 22.8 & 350.59 & 306.88 & 4.49 & Herrin(1968) \\
\hline SJG & Q & $\mathrm{P}$ & 24.13 & 108.48 & 309.32 & -6.31 & Herrin(1968) \\
\hline NVAR & & $\mathrm{P}$ & 25.7 & 301.48 & 329.95 & -0.29 & Herrin(1968) \\
\hline YKA & & $\mathrm{P}$ & 38.21 & 341.94 & 443.65 & 3.86 & Herrin(1968) \\
\hline ILAR & & $\mathrm{P}$ & 51.09 & 332.6 & 544.3 & 1.87 & Herrin(1968) \\
\hline
\end{tabular}

Column headings are as follows:

"Station" -Abbreviation of seismographic station or recording site at which the datum was observed. Most station abbreviations are internationally recognized standard abbreviations for seismographic stations that were installed to record earthquakes and that are intended to remain fixed at the same locations for decades or longer (U.S. Geological Survey, 2007). Abbreviations marked with asterisks $(*)$ correspond to locations of data from the Atlantis array or the CGG Green Canyon phase VIII multi-client survey (table 4); these abbreviations are "ad hoc" abbreviations used for this study alone.

"Quality" - "Q" denotes that the USGS/NEIC analyst judged the phase pick to be "questionable."

"Phase" - type of seismic-phase, as discussed in the text. The preferred hypocenter was obtained using the arrival times of the $P$-phases only. The other phases were considered in explorations that are discussed in the section entitled, "A test of other approaches to calculating the epicenter of the Green Canyon event from seismic phase arrival-times."

"Distance" - distance between the station and the epicenter, in degrees of great-circle path.

"Azimuth" - azimuth from epicenter to station, measured in degrees clockwise from north.

"Arrival-time" - observed phase arrival-time, measured in seconds with respect to the inferred origin-time at

04:14:22.2 UTC. Thus, the "AA603" arrival time of 11.2s corresponds to an absolute arrival-time of 04:14:33.4 UTC. 
Table 3. Continued.

"Residual" - observed phase arrival-time minus the theoretical arrival-time that is predicted from the epicentral distance, velocity model, and hypocenter location.

"Model" - velocity model that was used to compute the theoretical arrival-time. "Herrin(1968)" refers to the velocity model of Herrin and others (1968). " $2.90 \mathrm{~km} / \mathrm{s}$ ", "1.69 km/s", and " $1.5 \mathrm{~km} / \mathrm{s}$ " are velocities taken for three later arriving phases that are assumed to be surface-waves or sound waves in water; see the section entitled, "A test of other approaches to calculating the epicenter of the Green Canyon event from seismic phase arrival-times."

Table 4. Abbreviations and geographic coordinates of reference points of the Atlantis array groupings from which arrival times were obtained and of the CGG Green Canyon phase VIII multi-client survey.

\begin{tabular}{|c|c|c|c|c|c|c|c|}
\hline \multirow{2}{*}{$\begin{array}{c}\begin{array}{c}\text { Abbreviation } \\
\text { (table 3) }\end{array} \\
\text { AA135 }\end{array}$} & \multicolumn{3}{|c|}{$\begin{array}{l}\text { Latitude } \mathrm{N} . \\
\text { degrees minutes } \\
\text { seconds }\end{array}$} & \multicolumn{3}{|c|}{$\begin{array}{l}\text { Longitude W. } \\
\text { degrees minutes } \\
\text { seconds }\end{array}$} & \multirow{2}{*}{$\begin{array}{c}\text { Full name } \\
\text { Atlantis receiver-array } 135\end{array}$} \\
\hline & 27 & 12 & 8 & 90 & 2 & 23 & \\
\hline AA176 & 27 & 13 & 11 & 90 & 2 & 38 & Atlantis receiver-array 176 \\
\hline AA360 & 27 & 12 & 48 & 90 & 1 & 0 & Atlantis receiver-array 360 \\
\hline AA583 & 27 & 13 & 14 & 89 & 59 & 30 & Atlantis receiver-array 583 \\
\hline AA603 & 27 & 15 & 22 & 90 & 0 & 29 & Atlantis receiver-array 603 \\
\hline AA826 & 27 & 15 & 48 & 89 & 59 & 2 & Atlantis receiver-array 826 \\
\hline AA903 & 27 & 14 & 2 & 89 & 57 & 28 & Atlantis receiver-array 903 \\
\hline CGG-GC & 26 & 59 & 47 & 90 & 45 & 21 & $\begin{array}{l}\text { CGG Green Canyon phase } \\
\text { VIII multi-client survey }\end{array}$ \\
\hline
\end{tabular}

\section{Data Contributed by the Atlantis Array}

The Atlantis array, operated by BP in partnership with BHP Billiton Limited, consisted of nearly a thousand Fairfield Industries Z-3000 ocean-bottom nodes, sequentially deployed in two patches (Ross and Beaudoin, 2006). Fairfield Industries was also the prime contractor, responsible for deploying and retrieving the nodes and recovering the data from the nodes. At the time of the Green Canyon earthquake, the array comprised 491 live instrument-packages, spread out over an area of the ocean floor with dimensions of about 10 kilometers by 6 kilometers at water depths of 1,340 to 2,200 meters (Dellinger and Ehlers, 2007). Each instrument package contained a pressure sensor and three orthogonal $10 \mathrm{~Hz}$ seismometers. The data from the three seismometers were processed to vertical, north-south, and east-west motion (Dellinger and others, 2002). The Atlantis array was designed to record seismic signals at a higher range than frequencies typically associated with earthquakes recorded at epicentral distances of several tens of kilometers, but examination of Atlantis array data that were fortuitously recorded at the time of the Green Canyon event revealed that earthquake signals could be identified within the Atlantis array data stream (Dellinger and others, 2006; Dellinger and Ehlers, 2007).

Atlantis array $P$-wave arrival times that were used to locate the Green Canyon event were obtained visually from seven groupings, or receiver arrays, of Atlantis nodes. Each grouping included a central receiver that was sensitive to a particular component of motion (vertical, northsouth, east-west, or pressure) and all other receivers sensitive to the same component and situated within 1400 horizontal meters and 100 vertical meters of the central receiver. The groupings were chosen to avoid problems from complex topography within the area spanned by the Atlantis array. Data within each receiver array were filtered in several ways and slant-stacked assuming a variety of phase-velocities and azimuths-of-approach. Figure 4 illustrates a record section that was among 
the most effective at revealing the initial $P$-wave motion. For the record section of figure 4 , data from vertical-motion sensors were filtered with a BP in-house filter having a center frequency of 2 $\mathrm{Hz}$, and then slant-stacked using a phase velocity of $18.6 \mathrm{~km} / \mathrm{s}$ and an azimuth-of-approach of $316^{\circ}$.

The appearance of the $P$-waveform as recorded on the Atlantis array is much different than the impulsive $P$-wave that would typically be recorded by a seismograph situated on hard rock at comparable distances from an $M_{s} 5.3$ earthquake whose hypocenter was in highly elastic, crystalline rock. The data (see the lower plot in fig. 4) show that the energy grew steadily throughout a period of several tens of seconds following the initial $P$-onset. The emergent beginning of the Green Canyon event as recorded on the Atlantis array probably is due in part to extreme scattering of $P$-wave energy by the very heterogeneous velocity structure of the sedimentary section beneath the Gulf of Mexico, which includes thick deformed, relatively high velocity salt layers within low velocity sediments (Peel and others, 1995). The emergent beginning of the $P$-waves may also reflect a source process that lasts longer and is more complex than would be typical for an $M_{s} 5.3$ earthquake occurring in highly elastic crystalline, rock (Richter, 1958; Kovach, 1974). 
Z Comp., $2 \mathrm{~Hz}, \mathrm{~A}: \mathrm{v}=18200 \mathrm{~m} / \mathrm{s}$ az $=316$

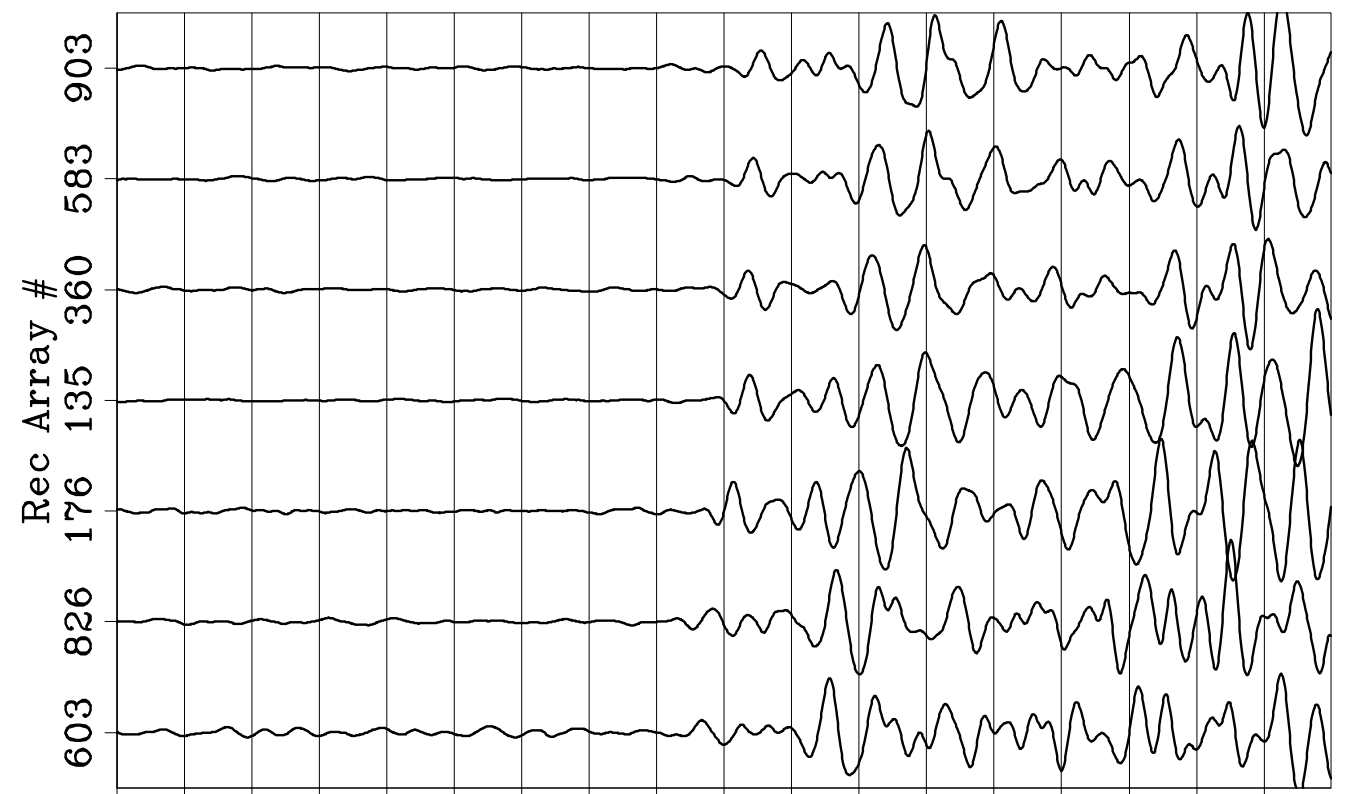

$252627282930 \quad 3132 \quad 33 \quad 34 \begin{array}{lllllllll}36 & 37 & 38 & 39 & 40 & 41 & 42\end{array}$

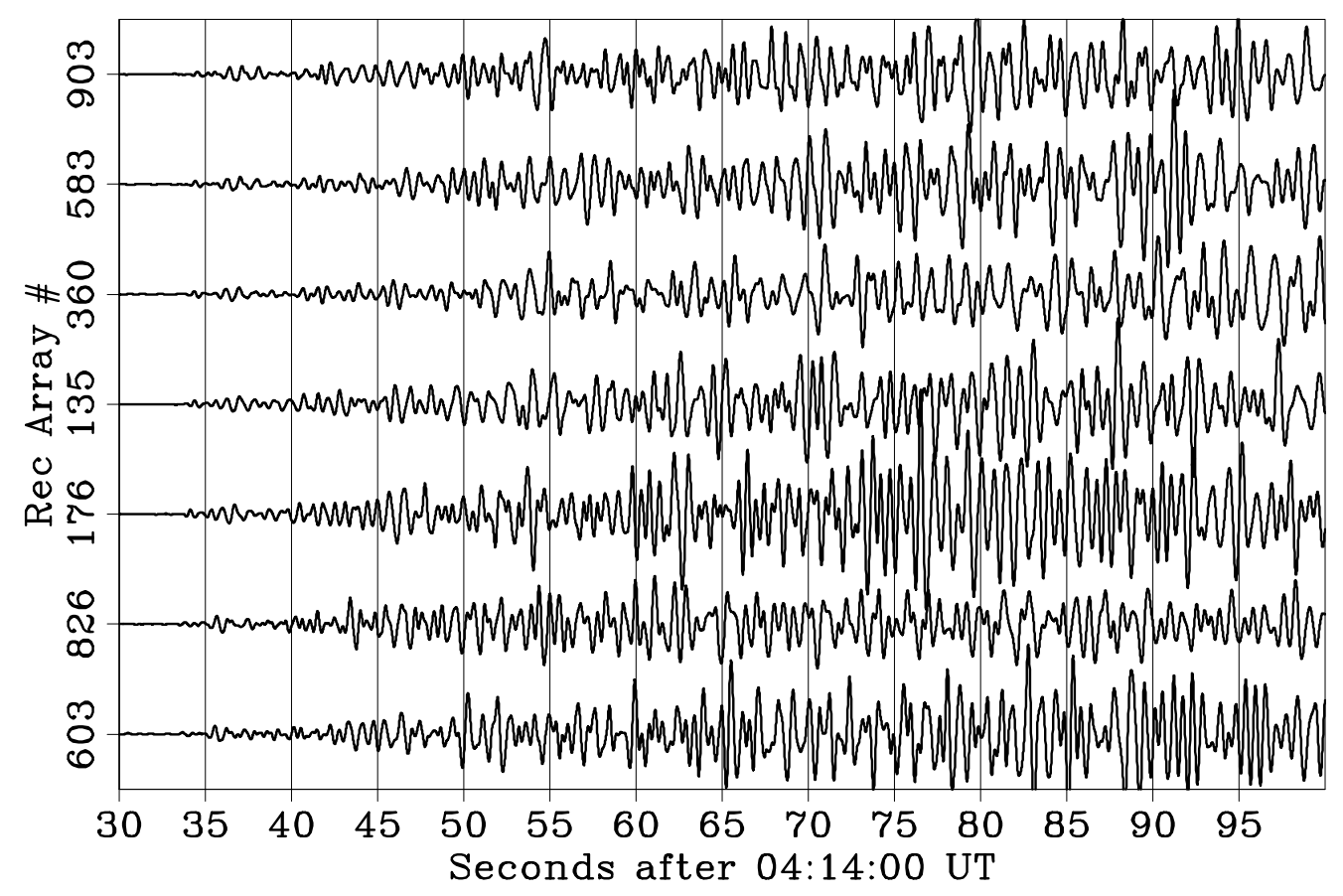

Figure 4. Vertical-component data from the Atlantis array, filtered, grouped into receiver arrays, and slant-stacked, as used for interpreting Atlantis array P-phase times of table 3. Upward motion is positive. The same data are plotted at two different time and amplitude scales. The top plot shows that there is a pickable first arrival. The bottom plot shows how the amplitude dramatically increases over the subsequent several tens of seconds. Receiver-array numbers are those used in table 4 . Interpreted $P$-time arrivals range between 04:14:33.3, for array 826, to 04:14:34.2 for receiver-array 903. 
Because of the strength of later arrivals in the Atlantis data (fig. 4), we explored the use of these arrivals in the location process. For example, consider the intermediate-amplitude energy that arrives beginning 04:14:50 - 04:14:55 in figure 4. This energy looks like a more coherent phase arrival when viewed on the seismograms that record EW motion, with the signal passed through a filter with a central frequency of $1 \mathrm{~Hz}$ (fig. 5). The phase propagates across the Atlantis array with an apparent velocity of about $2.9 \mathrm{~km} / \mathrm{s}$ (Dellinger and others, 2006), and the slant-stack of figure 5 was accordingly made with an apparent velocity of $2.9 \mathrm{~km} / \mathrm{s}$. We labeled this phase the " $U G 1$ " phase, for "upper-crustal guided phase type 1" and attempted to incorporate it into the location process. The preferred hypocenter of table 1 and figure 3 was computed without using the $U G 1$ phase arrival. In the section entitled, "A test of other approaches to calculating the epicenter of the Green Canyon event from seismic phase arrival-times," however, we discuss an attempt to include the $U G 1$-phase in the location process, assuming that the phase traveled as a direct phase from the same locus of energy-release as the $P$-wave arrivals of figure 4 with a phase velocity of $2.9 \mathrm{~km} / \mathrm{s}$.

E Comp., $1 \mathrm{~Hz}, \mathrm{E}: \mathrm{v}=2900 \mathrm{~m} / \mathrm{s}$ az $=352$

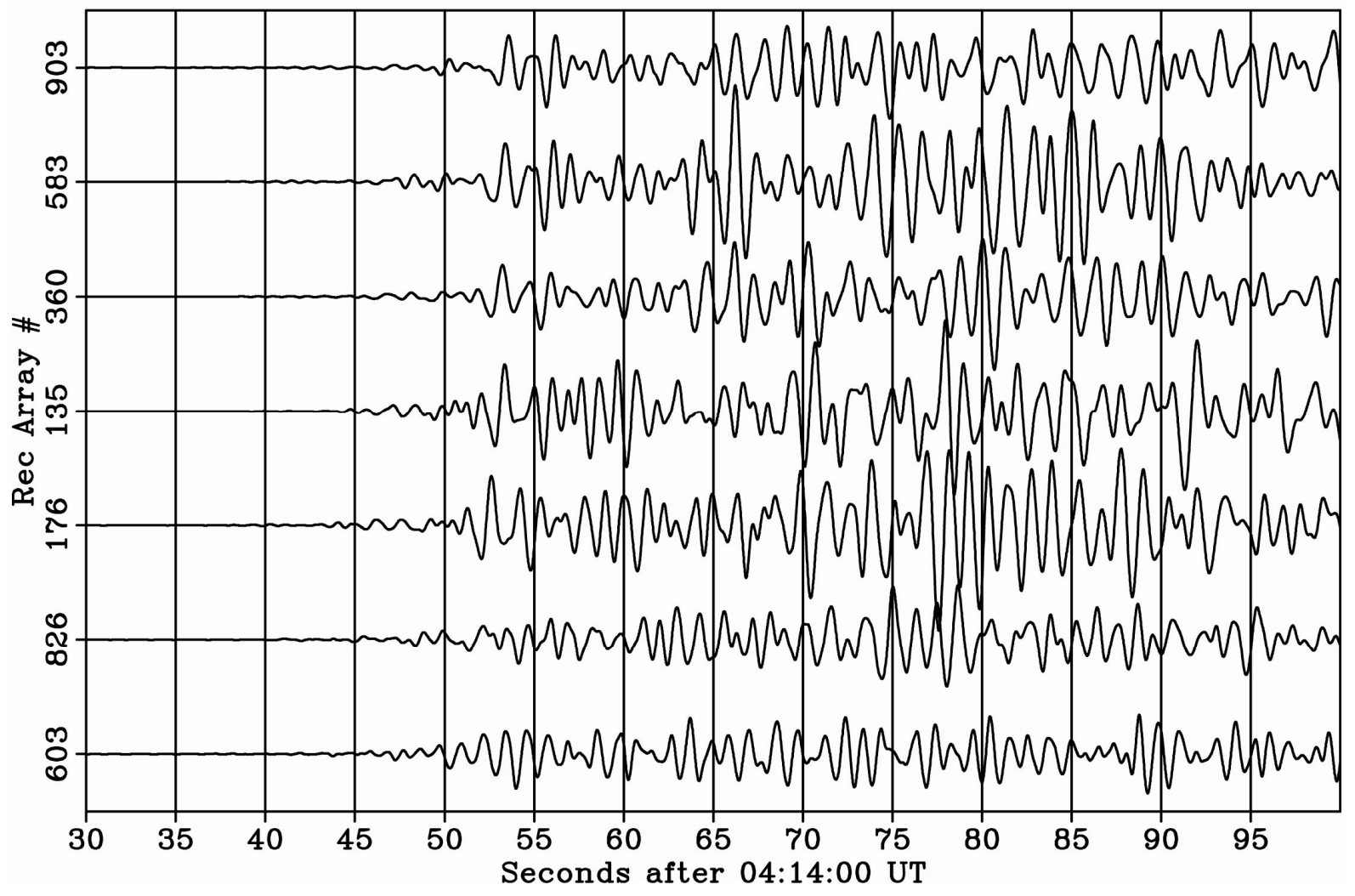

Figure 5. Atlantis array east-west component data that have been filtered, grouped into receiver arrays, and slant-stacked with an apparent velocity of 2,900m/s, as used for interpreting Atlantis array UG1-phase times of table 3. Westward motion is positive. Receiver-array numbers are those used in table 4. Interpreted UG1-arrivals range between 04:14:51.7, for array 176, and 04:14:52.5 for receiver-array 903 , with no arrivals interpreted for arrays 603 or 826 , the two receiver arrays located over salt. 
Consider next the high-amplitude energy that arrives at about 04:14:70 in figure 4. From several attempts to isolate this energy with different slant-stacks of different components, we found that the phase appeared most coherent when viewed on vertical component sensors, passed through a filter with a central frequency of $1 \mathrm{~Hz}$, and filtered with an apparent velocity of $1.69 \mathrm{~km} / \mathrm{s}$ (fig. 6). We labeled this phase the "UG2" phase, for "upper-crustal guided phase type 2" and tried to incorporate it into the location process. The preferred hypocenter of table 1 and figure 3 was computed without using the UG2-phase arrival. In the section entitled, "A test of other approaches to calculating the epicenter of the Green Canyon event from seismic phase arrival-times," however, we discuss an attempt to include the $U G 2$-phase in the location process, assuming that the phase traveled as a direct phase from the same locus of energy-release as the $P$-wave arrivals of figure 4 with a phase velocity of $1.69 \mathrm{~km} / \mathrm{s}$.

Z Comp., $1 \mathrm{~Hz}, \mathrm{~F}: \mathrm{v}=1690 \mathrm{~m} / \mathrm{s}$ az $=338$

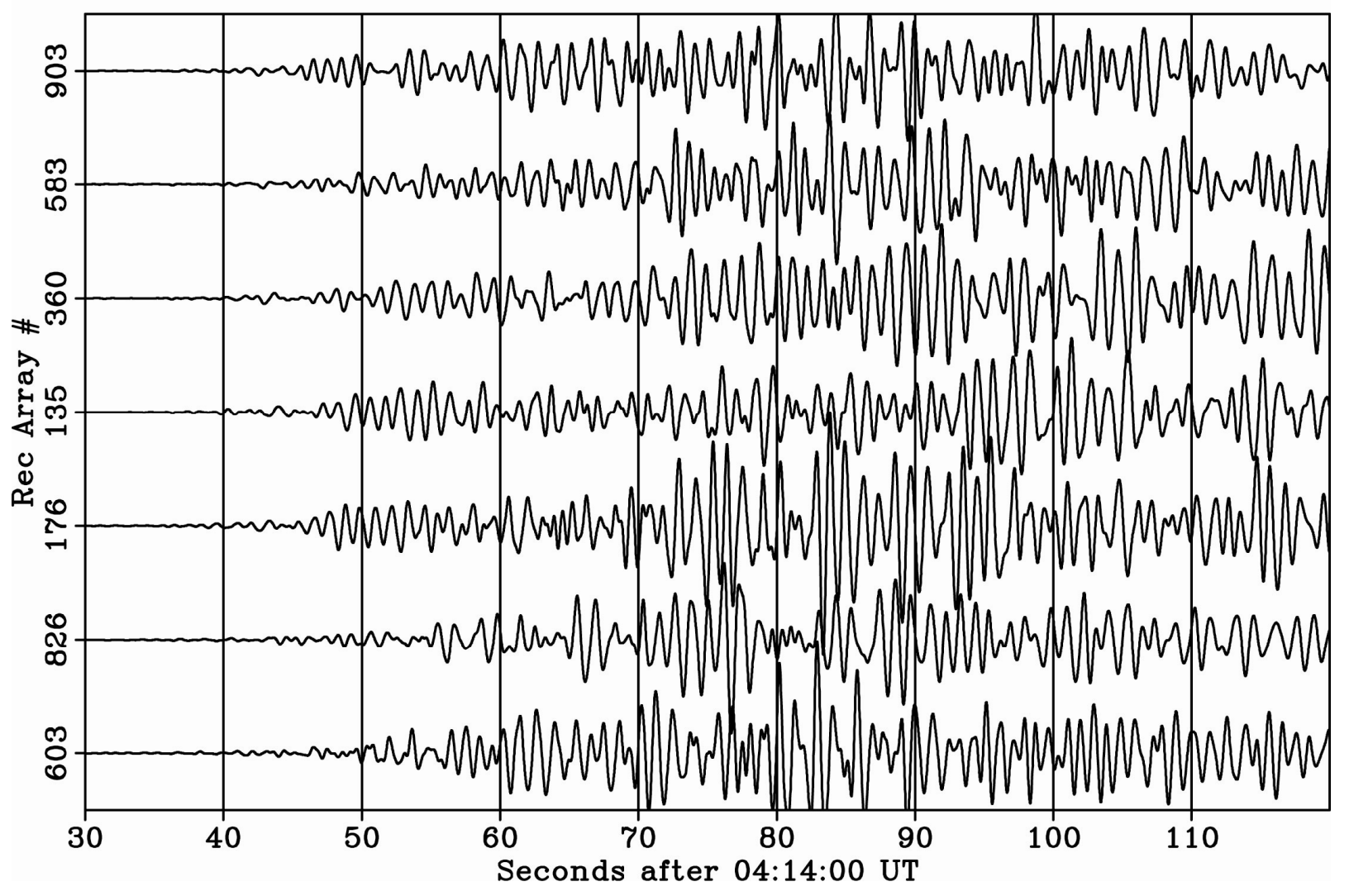

Figure 6. Atlantis array vertical-component data that have been filtered, grouped into receiver arrays, and slant-stacked with an apparent velocity of 1,690 m/s, as used for interpreting Atlantis array UG2-phase times of table 3. Upward motion is positive. Receiver-array numbers are those used in table 4. Interpreted UG2-arrivals range between 70 seconds after 04:14:10 (04:15:10) for arrays 603 and 826, to 72 seconds after 04:14:10 (04:15:12) for receiver-arrays 360, 583, and 903. 


\section{Data Contributed by the CGG Green Canyon Phase VIII Multi-Client Survey}

The CGG Green Canyon phase VIII multi-client survey provided data from six parallel cables with hydrophones attached, towed from a boat that was moving from east to west. Each string of hydrophones was $9 \mathrm{~km}$ long. The hydrophones were towed at depths of 9 meters. Data acquisition from the hydrophones was timed to coincide with arrivals of seismic signal generated by an air-gun. Signal from the Green Canyon event was thus superimposed on the air-gun signal. Substantial data-processing was required to extract the Green-Canyon-event signal from the survey data, and the search for the Green-Canyon-event signal was guided by knowledge of the hypocenter and origin time derived from the Atlantis array and USGS/NEIC data alone. Specifically, we expected that the $P$-wave as recorded by the CGG Green Canyon phase VIII multi-client survey would arrive later than the $P$-wave on the Atlantis array and would be characterized by a high apparent velocity across the survey array. The $P$-wave arrival-time of table 3 corresponds to a peak of seismic energy in the time-series of figure 7 that satisfies the conditions of having a high apparent velocity and arriving later than the $P$-wave at the Atlantis array. We consider it very likely that the phase arrival identified in figure 7 is part of the $P$-wave signal from the Green Canyon event, although we cannot rule out that a slightly earlier, smaller amplitude $P$-wave arrival is hidden in the noise before the pick identified in figure 7. 
shot $3921,04: 14: 18.9$

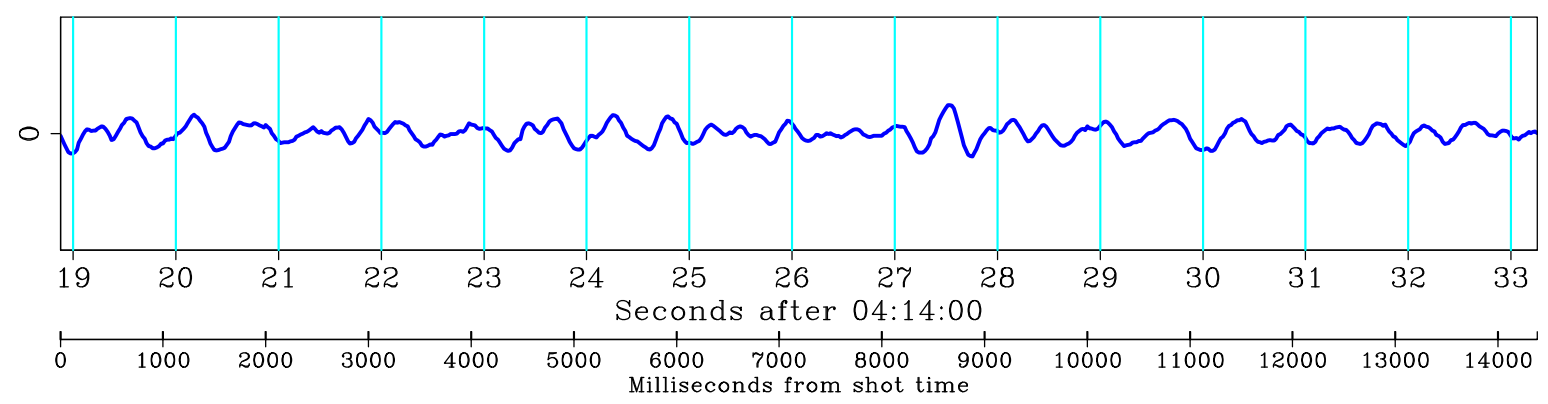

shot $3920,04: 14: 34.1$

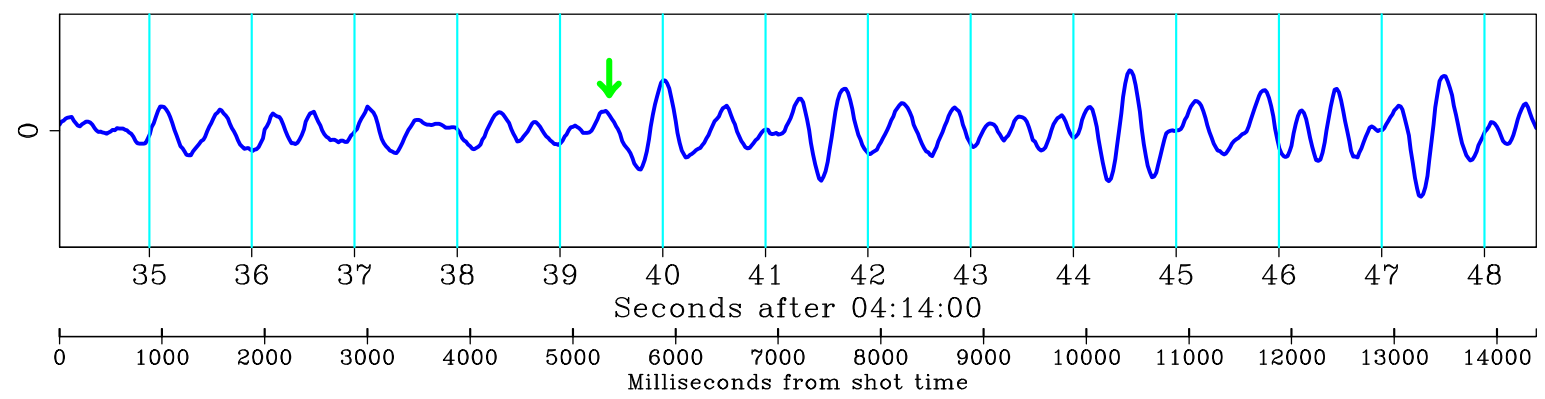

shot $3919,04: 14: 49.4$

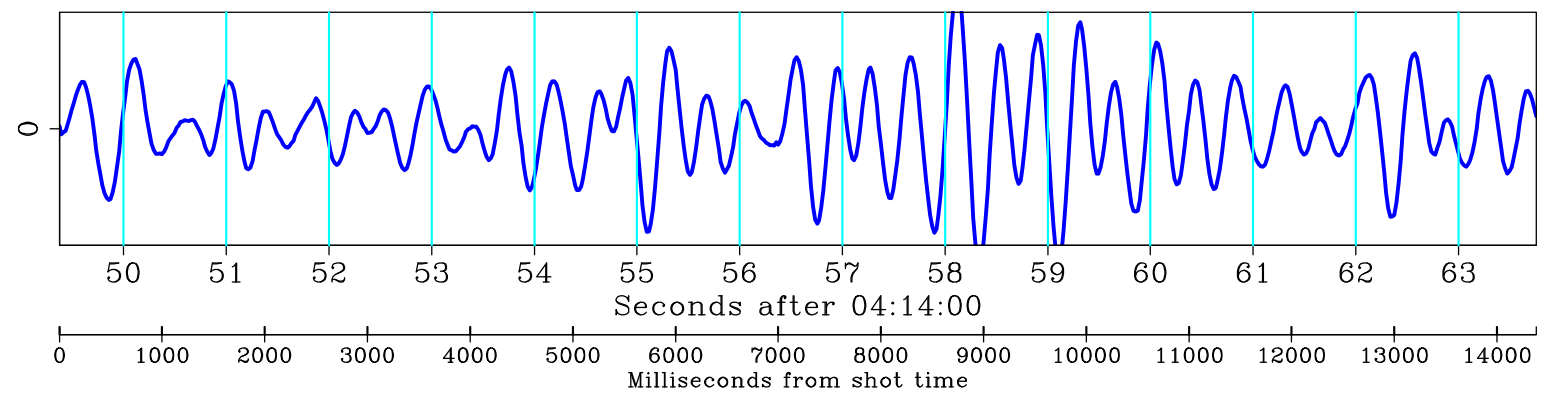

Figure 7. Three successive shots from the CGG Green Canyon phase VIII multi-client survey data stacked over the entire towed-streamer array, revealing an arrival (at time 04:14:39.5, marked by the green arrow) that we interpret as the initial $P$-wave arrival associated with the Green Canyon event. A positive displacement indicates a decrease in pressure. Data were filtered to suppress the much higher frequency air-gun signal and a low-frequency signal generated by ocean swell. Early earthquake arrivals had a distinctive high phase velocity across the array, which aided in their identification. The three shots are plotted to the same scale. These data also show a small initial arrival followed by gradually increasing amplitudes over the next several tens of seconds, as was observed in the Atlantis data. Data courtesy CGG Veritas, Houston, Texas. 


\section{Data Obtained from the Routinely Processed USGS/NEIC Data-Stream}

Figure 8 shows examples of recordings of the Green Canyon event for which USGS/NEIC analysts interpreted $P$-wave arrival-times that were used for the calculation of the preferred hypocenter (table 3 ). Readings made from the routinely processed USGS/NEIC data-stream were all made at epicentral distances of $5.36^{\circ}$ and greater. Figure 8 illustrates the characteristically emergent nature of the $P$-wave at USGS/NEIC stations, which made difficult the exact identification of the times of the $P$-wave arrival. An unusually high percentage of $P$-wave arrivaltimes picked by NEIC were identified as "questionable" interpretations. The 18 questionable readings out of 34 teleseismic readings reported for the $M_{s} 5.3$ Green Canyon event (table 3) contrasts with the typical 1 or 2 percent of readings expected to be questionable for a mid-plate earthquake of this size. The large number of questionable teleseismic $P$-wave observations is probably a reflection of the emergent nature of the $P$-wave signals and may also reflect the general difficulty of identifying the event's low short-period $P$-wave amplitude (reflected in the event's low $m_{b}$ value) in the background of microseismic noise.
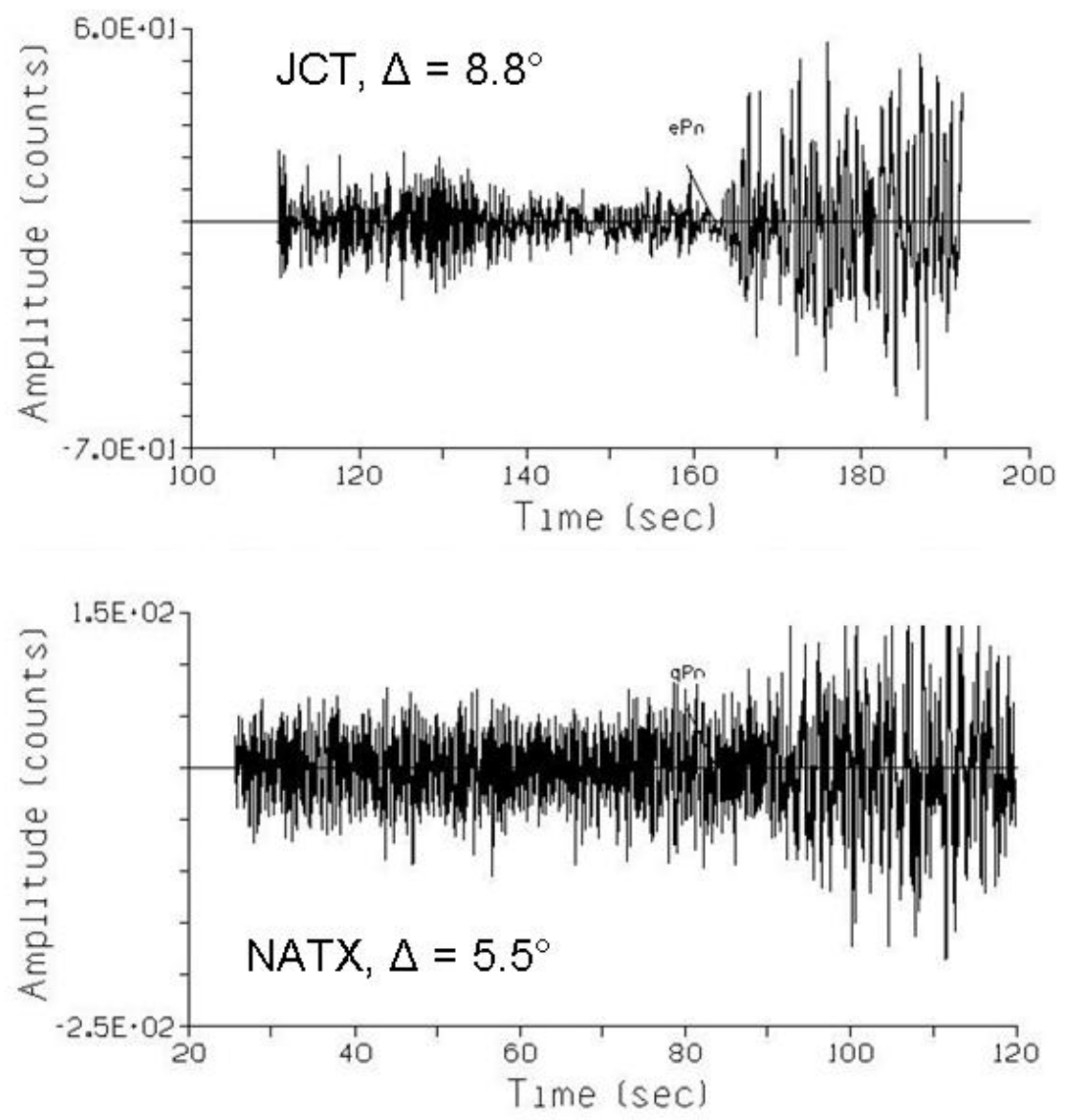

Figure 8. Examples of USGS/NEIC $P$-wave arrival-time. The top plot shows an arrival at station JCT (Junction, Texas) that was not judged questionable by the NEIC analyst. The bottom plot shows an arrival at station NATX (Nacogdoches, Texas) that was judged "questionable" by the NEIC analyst. Both signals are filtered to enhance high-frequency motion. Note that the time window for JCT differs from the time window shown in figure 2. 
The $P$-wave residuals (observed arrival-times minus calculated arrival-times) for the USGS/NEIC stations in table 3 (those at a distance of $5.36^{\circ}$ and greater) show a scatter that is large (standard error about $4 \mathrm{~s}$ ) by comparison with residuals that are commonly observed (standard error typically about $1 \mathrm{~s}$ ) with today's teleseismically recorded earthquakes. The high scatter is probably due to the difficulty of identifying the initial $P$-wave, discussed in the previous paragraph, and to the travel-time tables of Herrin and others (1968) not adequately reflecting the seismic-wave velocities on the raypaths between the epicenter of the Green Canyon event and some of the teleseismic seismographic stations, as discussed at the beginning of this section.

\section{A Test of Other Approaches to Calculating the Epicenter of the Green Canyon Event from Seismic Phase Arrival-Times}

In the previous section, we summarized the data and modeling assumptions used to calculate the preferred hypocenter of table 1, and we also described shortcomings of the data and modeling assumptions, as well as seismic phases that we observed but did not use in calculating the preferred hypocenter.

In this section, we discuss additional epicenter calculations we made with different data, modeling assumptions, or seismic phases. Epicenters from example trial runs are shown in figure 9. The illustrated examples are a subset of a much larger number of trial epicenter calculations.

For the test cases illustrated in figure 9, we considered the earthquake at two possible focal depths: $2 \mathrm{~km}$ and $10 \mathrm{~km}$. For each focal depth, we considered four combinations of data from table 3:

1. Use of Atlantis and CGG Green Canyon phase VIII $P$-wave arrival-times together with all $P$ wave arrival-times from more distant stations.

2. Use of Atlantis and CGG Green Canyon phase VIII $P$-wave arrival-times together with $P$-wave arrival times from more distant stations that were not judged questionable by NEIC analysts.

3. Use of $P$-wave arrival-times from combination 2, with the addition of the Atlantis $U G 1$ and $U G 2$ phase arrival-times and with the addition of a CGG Green Canyon phase VIII arrival-time denoted $U G 3$ that corresponds to energy arriving with a velocity of about $1.5 \mathrm{~km} / \mathrm{s}$ (discussed in the next section, "Constraints on the epicenter of the Green Canyon event from the azimuth-ofapproach of seismic waves recorded by the Atlantis array and the CGG Green Canyon phase VIII multi-client survey").

4. Use of $P$-wave arrivals from stations more distant than Atlantis and CGG Green Canyon phase VIII together with Atlantis $U G 1$ and $U G 2$ phase arrival times and CGG Green Canyon phase VIII $U G 3$ phase arrival time, but with no Atlantis or CGG Green Canyon phase VIII $P$-wave arrival-times.

The preferred solution is equivalent to approach 1 , but with the depth restrained to $5 \mathrm{~km}$. 


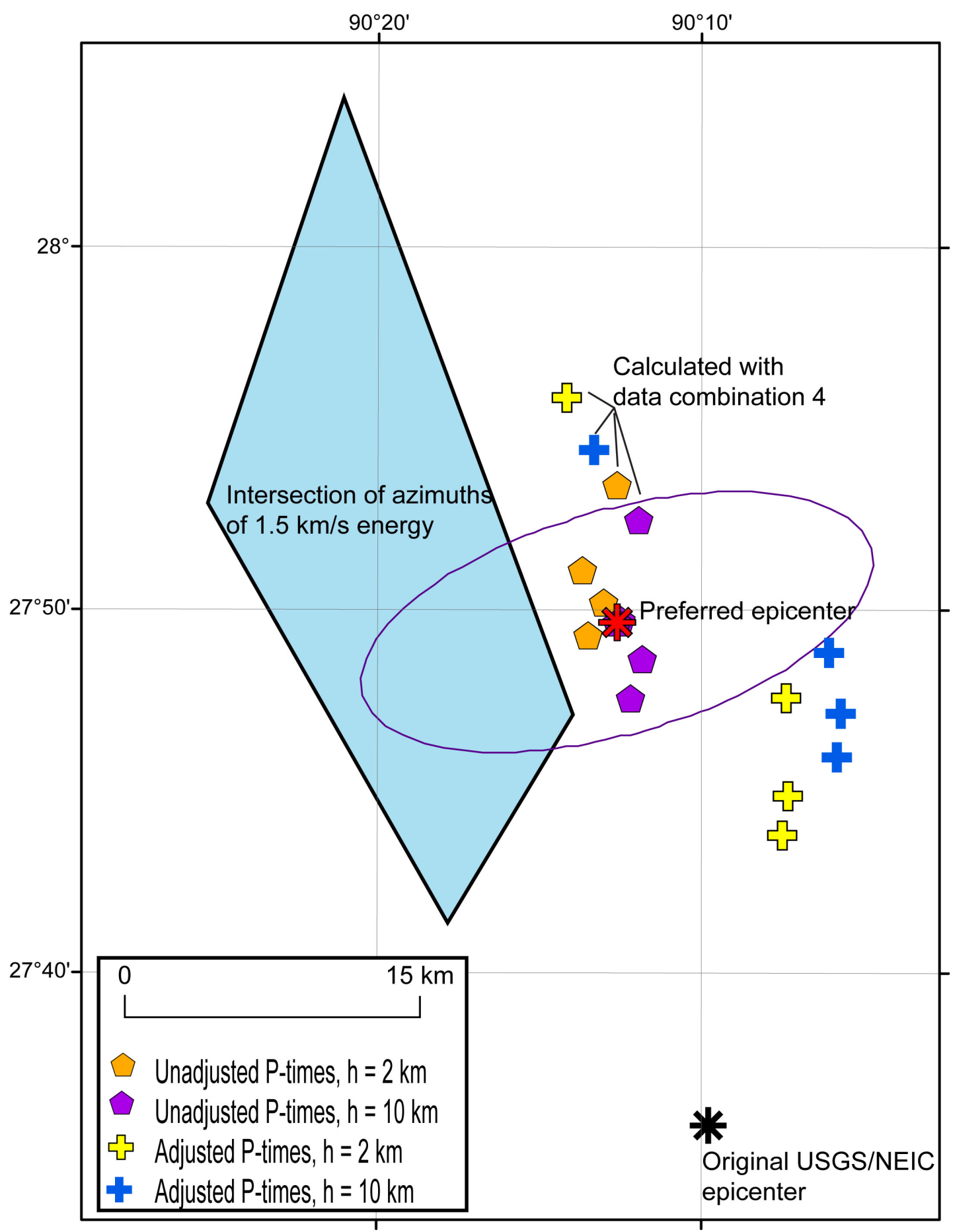

Figure 9. Epicenters calculated for the Green Canyon event using two different focal depths, different combinations of phase arrival times, and different arrival times that are adjusted and not adjusted for differences between a local velocity model and the global velocity model of Herrin and others (1968). The region of intersection of azimuths-of-approach of energy recorded at the Atlantis array and the CGG Green Canyon phase VIII multi-client survey is plotted from figure 3. The original and final USGS/NEIC epicenters are also shown, as is the $90 \%$ epicentral confidence ellipse that is associated with the preferred epicenter. 
For the eight depth-data combinations just listed, we tried locating the events using the times unadjusted, with no attempt to account for differences between local structure and the global model. This is the approach that would have been followed if the Atlantis and CGG Green Canyon phase VIII data had come from seismographs designed to record earthquake signal and had been received by the NEIC through the normal NEIC data channels. For the eight depth-data combinations we also adjusted arrival-times to account for differences between the global model and a model that more accurately depicts local velocities. Considering the two approaches to modeling the travel-times, and the eight depth-data combinations, we have 16 trial attempts represented in figure 9.

For adjusting $P$-wave arrival times to account for differences between the global model and probable local velocity structure, we used the model of table 5 . Water depth is assumed to be $2 \mathrm{~km}$, a value typical of the ocean floor where the Atlantis array was placed. The sedimentary section at depths between $2 \mathrm{~km}$ and $15 \mathrm{~km}$ is taken to have a velocity equal to the average velocity of $P$ waves traveling vertically through a typical column of salt layers and soft sedimentary rock that was provided to us by Frank Peel of BHP Billiton (written commun., 2007). The deeper velocities and thickness are abstracted from models of Ebeniro and others (1988) for the northwestern Gulf of Mexico.

Table 5. Velocity model that is used in a test to adjust the $P$-wave arrival-times for the effect of the Earth's crust beneath the Gulf of Mexico, (1), being thinner, (2), having a slower $P$-wave velocity, and, (3), overlying a mantle with a higher $P$-wave velocity, than assumed in the model of Herrin and others (1968). Epicenters calculated with the adjusted $P$-wave times are discussed in the text and shown in figure 9 , but ultimately we prefer an epicenter computed with the model of Herrin and others (1968).

\begin{tabular}{cc}
\hline $\begin{array}{c}\text { Depth to top of layer } \\
(\mathbf{k m})\end{array}$ & $\begin{array}{c}\text { P-wave velocity (km/s) within } \\
\text { layer }\end{array}$ \\
\hline 2.0 & 3.83 \\
15.0 & 6.0 \\
20.0 & 8.4 \\
\hline
\end{tabular}

Our accounting for differences between the global model and local velocity structure is approximate. For arrival-time adjustments for $P$-waves recorded by the Atlantis array and the CGG Green Canyon phase VIII multi-client survey, we took simply the differences between the traveltimes predicted by the model of table 5 and those predicted by the model of Herrin and others (1968) for epicentral distances of $0.6^{\circ}$ (Atlantis) and 1.0 (CGG Green Canyon phase VIII). For arrival-time adjustments for all $P$-waves recorded at regular USGS/NEIC stations, we took the difference in the travel-times predicted by the model of table 5 and the model of Herrin and others (1968) for rays propagating downward from the assumed focal depth (2 or $10 \mathrm{~km}$ ) to a depth of 40 $\mathrm{km}$ at an angle of $30^{\circ}$ from vertical. Theoretical travel times for the phases $U G 1, U G 2$, and $U G 3$ were taken as the quotients of epicentral distances divided by the phase velocities (given in the "Model" column of table 3). These approximations are sufficient to explore the general effect of low-velocity sediments on the epicenter calculation. A significantly more exact analyses, with raytracing through three-dimensional velocity models, for example, would require a research effort that is beyond us. Such an effort might not yield a more confident resolution of the hypocenter than our approximate effort, in view of the low precision of the $P$-wave readings and in view of 
lack of knowledge of the velocity structure between the source region and many of the recording stations.

Epicenters resulting from all trials are north of the original USGS/NEIC epicenter (fig. 9). Epicenters and origin times can be found that are consistent with the Atlantis and CGG Green Canyon phase VIII $P$-wave arrival-times and with the USGS/NEIC $P$-wave arrival-times. The epicenters calculated with adjusted $P$-times are 10 to $15 \mathrm{~km}$ southeast or east-southeast of the epicenters calculated with unadjusted $P$-times. Changing the focal depth by $8 \mathrm{~km}$ also changes the position of the calculated epicenter by several kilometers. Data combination 4, which includes the Atlantis and CGG Green Canyon phase VIII $U G 1, U G 2$, and $U G 3$ arrivals but not those stations' $P$-wave arrivals, used in conjunction with the USGS/NEIC $P$-wave arrivals, produced the epicenters that were most to the north of the preferred epicenter.

The arrival times of the Atlantis $U G 1$ and $U G 2$ arrivals cannot be reconciled with the USGS/NEIC $P$-wave arrivals and the Atlantis and CGG Green Canyon $P$-wave arrivals, unless the velocities of the Atlantis $U G 1$ and $U G 2$ phases are significantly slower than assumed in table 3 , or unless the $U G 1$ and $U G 2$ phases actually come from a different source than the initial $P$-wave, as might be the case if the source were an extended submarine landslide. As seen from table 3, with the preferred hypocenter (that calculated with the unadjusted $P$-times) the $U G 1$ arrivals are systematically late by about $5.5 \mathrm{~s}$ and the $U G 2$ arrivals are systematically late by about $8 \mathrm{~s}$. The UGS and $U G 2$ arrivals are even later with respect to the hypocenters calculated with the adjusted $P$-times.

It is noteworthy that the set of epicenters resulting from the different model assumptions of figure 9 spans an area with a much different orientation than the formal $90 \%$ confidence ellipse that is associated with the preferred epicenter. Our conclusion that the uncertainty of the event is about $+/-15 \mathrm{~km}$ in any azimuth, at a $90 \%$ level of confidence, takes into account both the formal uncertainty implied by the confidence ellipse and the uncertainty suggested by the exploration of different model assumptions.

\section{Constraints on the Epicenter of the Green Canyon Event from the Azimuth-of-Approach of Seismic Waves Recorded by the Atlantis Array and the CGG Green Canyon Phase VIII Multi- Client Survey}

An estimated epicenter of the Green Canyon event may in principle be obtained independently of the USGS/NEIC arrival-time data by using azimuths of phase arrivals interpreted from the Atlantis array and the CGG Green Canyon phase VIII multi-client survey. A difficulty with using phase azimuth to locate the shock is that the azimuth changes as a function of the phase being considered (Dellinger and others, 2006; Dellinger and Ehlers, 2007). The initial $P$-wave (fig. 4) appears to approach the Atlantis array from an azimuth of $316^{\circ}$, for example, whereas the phase we are labeling " $U G 1$ " (fig. 5) approaches from an azimuth of $352^{\circ}$. Other phases have apparent azimuths-of-approach that are intermediate between $316^{\circ}$ and $352^{\circ}$. These different azimuths-ofapproach are probably due in part to raypaths departing from a great-circle path as a result of intense velocity inhomogeneity of the upper crust (Peel and others, 1995). If the source of the Green Canyon event were a giant landslide (Nettles, 2006, 2007), the different phase azimuths could also partly reflect the large source region of the event.

Figure 10 shows a visualization (Regone, 1997) of the Atlantis array data for energy that crossed the array with an apparent velocity of $1.5 \mathrm{~km} / \mathrm{s}$. Figure 11 shows a similar visualization of the energy that crossed the CGG Green Canyon phase VIII multi-client survey array with an 
apparent velocity of about $1.5 \mathrm{~km} / \mathrm{s}$. In figures 10 and 11 , we have also subjectively selected ranges of azimuths-of-approach for maxima of the earliest arriving 1,500 km/s energy at the two Gulf of Mexico arrays. In figures 3 and 9 we have plotted the area of intersection of these azimuths. The area of intersection is broadly consistent with the preferred epicenter, but also extends far beyond the limits of the formal $90 \%$ confidence ellipse that is associated with the preferred epicenter.

\section{Time=201965 Angle $=330$ Amp $=0.289$}
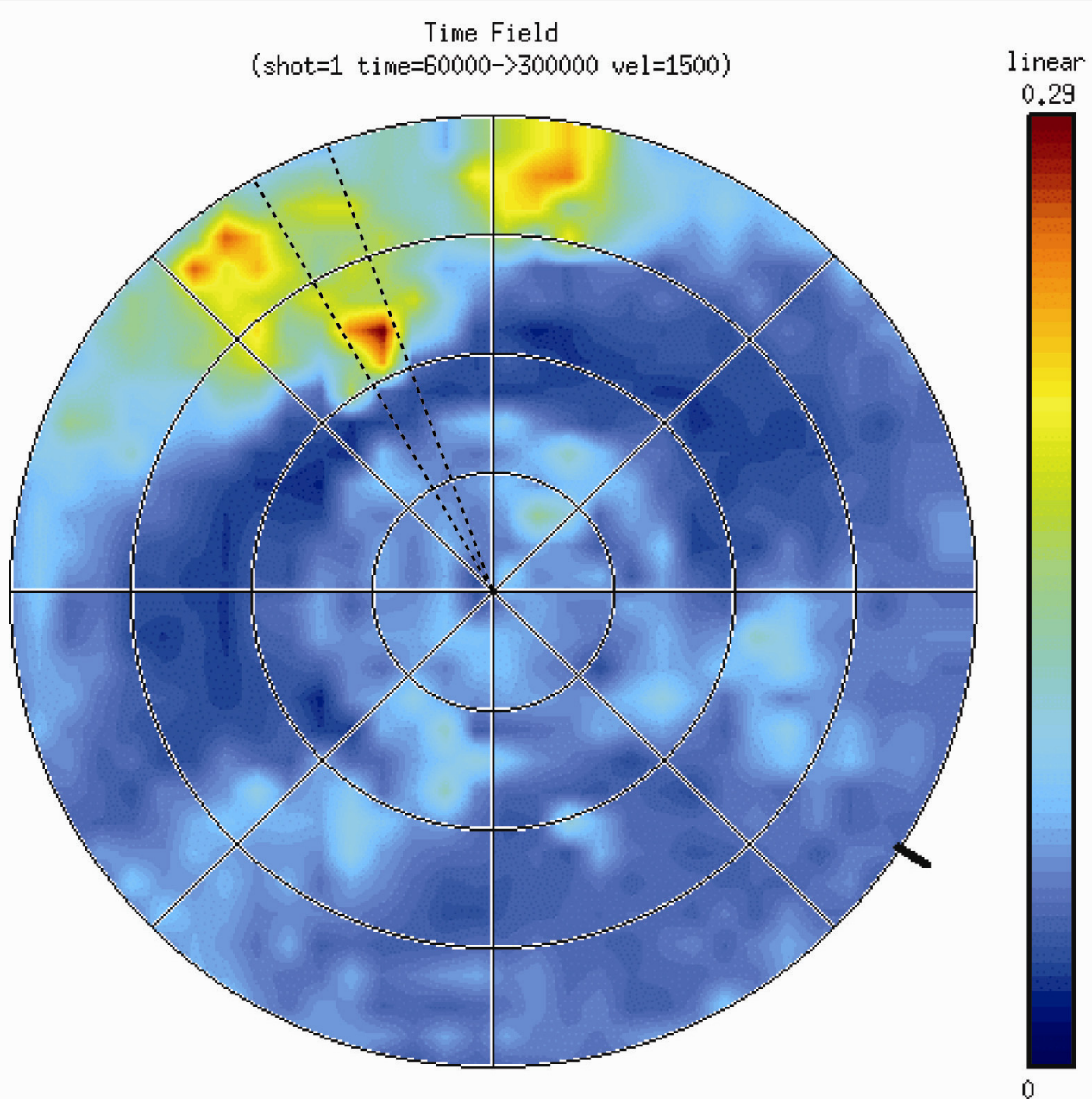

Figure 10. 1,500 km/s energy intensity recorded at the Atlantis array (color coded, with red being highest energy) as a function of azimuth (angular polar coordinate, with north pointing up) and time (radial polar coordinate, with the center of the circle representing 04:13:00 and the outer ring representing 04:17:00). The energy is calculated from slant stacks of all 491 live hydrophone nodes of the Atlantis array, summed for the given time and azimuth with a stacking velocity of $1,500 \mathrm{~m} / \mathrm{s}$, and referenced to the center of the array. The dashed radial lines bracket the range of azimuth of energy approach that we used to infer a range of epicenters from the intersection of azimuths of $1.5 \mathrm{~km} / \mathrm{s}$ arrivals (figs. 3,9 ). 


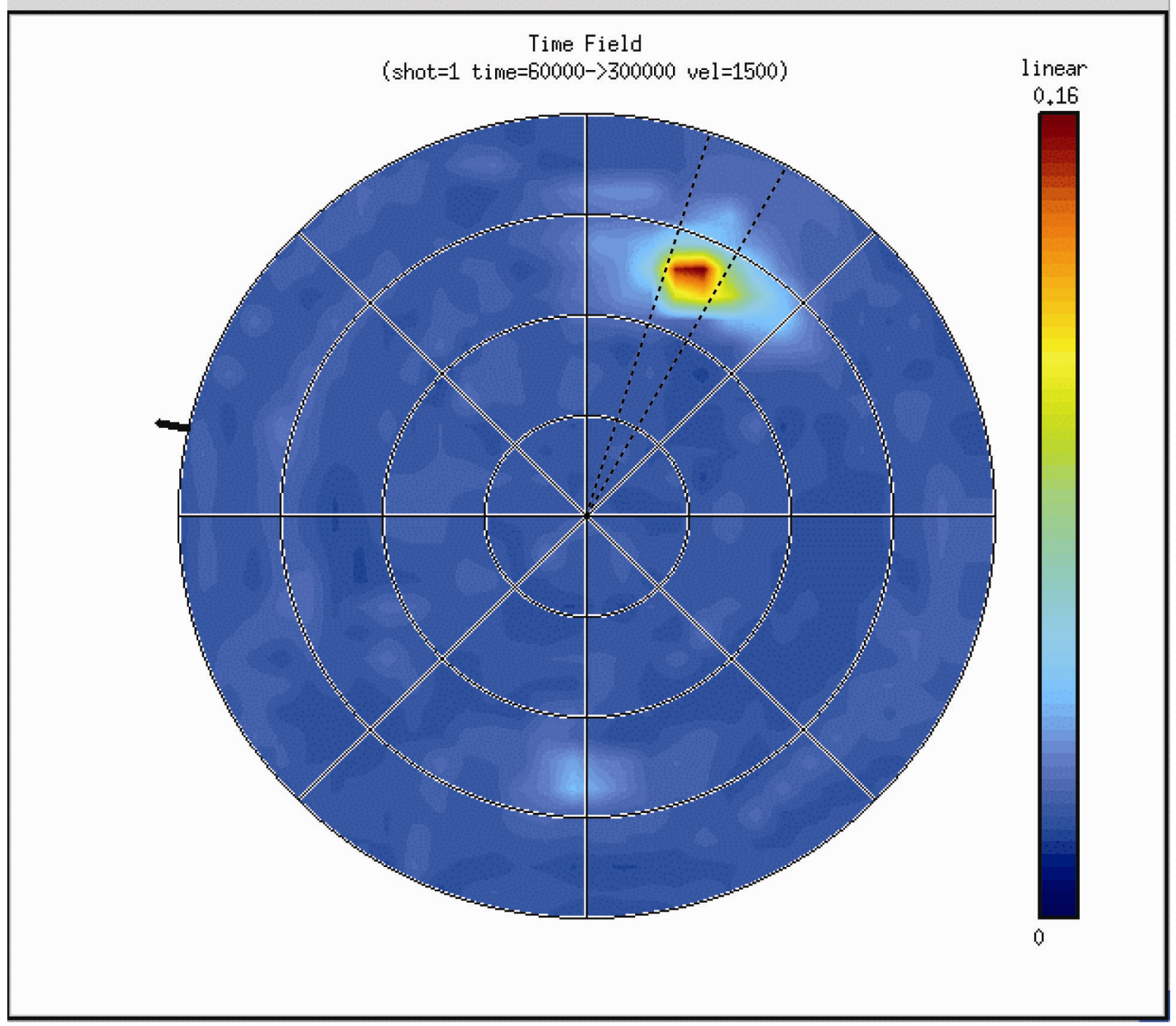

Figure 11. $1,500 \mathrm{~km} / \mathrm{s}$ energy intensity recorded by the CGG Green Canyon phase VIII multi-client survey (color coded, with red being highest energy) as a function of azimuth (angular polar coordinate, with north pointing up) and time (radial polar coordinate, with the center of the circle representing 04:13:00 and the outer ring representing 04:17:00). The energy is calculated from slant stacks of the nodes of the CGG Green Canyon phase VIII multi-client survey, summed for the given time and azimuth with a stacking velocity of $1,500 \mathrm{~m} / \mathrm{s}$, and referenced to the center of the array. The dashed radial lines bracket the range of azimuth of energy approach that we used to infer a range of epicenters from the intersection of azimuths of $1.5 \mathrm{~km} / \mathrm{s}$ arrivals (figs. 3, 9). Data courtesy CGG Veritas, Houston, Texas. 


\section{Concluding Remarks}

Although we are satisfied that the Atlantis array data and the CGG Green Canyon phase VIII multi-client survey data indicate that the Green Canyon event occurred from 10 to $40 \mathrm{~km}$ north of the USGS/NEIC epicenter that was calculated without data from these seismic exploration arrays, we are frustrated by discordances that remain in the data with respect to the preferred location. A prime example is that correcting for likely low velocities in the Earth's crust tends to move calculated epicenters east-southeast, whereas incorporating arrival-times of energy that arrives after the $P$-waves tends to move calculated epicenters to the north. We do not think the discordances are surprising, considering likely errors in interpreting $P$-wave arrival times and considering that our interpretations are based on models that vastly simplify the velocity structure of the Earth's crust offshore of southern Louisiana. If the Green Canyon event occurred as a result of a failure lasting many seconds, such as would occur in a large landslide, the discordances are even less surprising, because of the expected large source zone of such an event. Nonetheless, the end result is that the precision of our epicenter of the Green Canyon event is much worse than would be the case for the epicenter of an onshore magnitude 3 or 4 earthquake occurring in coastal California, for example.

A standard seismological tactic for obtaining higher precision locations of earthquakes in a given source region is to install continuously recording seismographs in the vicinity of the source region. An ocean floor seismometer in the region of the Green Canyon event would be operating in a noisier environment than is typical of, for example, onshore coastal California, and the frequency of earthquakes recorded by such a seismometer might be low. It is noteworthy, however, that the revised epicenter of the Green Canyon event lies near the USGS/NEIC epicenters of two earlier earthquakes - those of June 30, $1994\left(m_{b} 4.2\right)$ and December 9, $2000\left(m_{b} 4.2 ; M_{s} 4.3\right)$ (fig. 3). As with the epicenter of the Green Canyon event, the epicenters of the earlier events are likely not determined with high accuracy. Nonetheless, extrapolating from the times of the three events, it appears that a region with linear dimensions of several tens of kilometers may be experiencing an earthquake of greater than magnitude 4 one or two times a decade, on average. If the earthquakes in this region are more numerous still at lower magnitudes, in keeping with most seismic regions worldwide, one might expect 10 or 20 shocks of magnitude 3 and greater in an average decade. If the ocean bottom near the Green Canyon epicenter is sufficiently quiet that the signal of a magnitude 3 earthquake can be recorded at a distance of $50 \mathrm{~km}$, several years' operation of an ocean-floor seismometer tuned to frequencies typically recorded in earthquakes would have a reasonable chance of shedding significant light on the source of seismic events in this section of the Gulf of Mexico.

\section{Acknowledgments}

We are grateful to BP, BHP-Billiton, and CGG-Veritas for providing access to data from the Atlantis array and the CGG Green Canyon phase VIII multi-client survey. We are grateful to Fairfield industries for their cooperation in preserving the unique Atlantis earthquake dataset. We thank Frank Peel, BHP-Billiton, for insight into the shallow velocity structure of Gulf of Mexico sediments. Bruce Presgrave, USGS/NEIC, provided insight on USGS/NEIC operational procedures and called our attention to the unusual teleseismic broadband signal of the Green Canyon event (fig. 2). We benefited from helpful reviews by Gavin Hayes and Dan McNamara. 


\section{References Cited}

Dellinger, Joseph, Clarke, R., and Gutowski, P., 2002, Three-dimensional vector infidelity correction by general linear transform: Expanded abstracts of the European Association of Geoscientists and Engineers, Abstract E-05.

Dellinger, Joseph, Ehlers, J., and Clarke, R., 2006, The "Green Canyon" event as recorded by the Atlantis OBS node survey: Eos Transactions, American Geophysical Union, v. 87, no. 52, Suppl. 26 Dec. 2006, Abstract S53B-1330.

Dellinger, Joseph, and Ehlers, J., 2007, Low frequencies with a "dense" OBS array: The Atlantis Green-Canyon earthquake dataset, Society of Exploration Geophysicists Technical Program Expanded Abstracts, p. 36-40, doi:10.1190/1.2792377.

Dewey, J.W., 1971, Seismicity studies with the method of joint hypocenter determination: Berkeley, Calif., University of California, Ph. D. dissertation, 164 p.

Dokka, R.K., Sella, G.F., and Dixon, T.H., 2006, Tectonic control of subsidence and southward displacement of southeast Louisiana with respect to stable North America: Geophysical Research Letters, v. 33, L23308, doi:10.1029/2006GL027250, 5 p.

Ebeniro, J.O., Nakamura, Y., Sawyer, D.S., and O'Brien, W.P., 1988, Sedimentary and crustal structure of the northwestern Gulf of Mexico, Journal of Geophysical Research, v. 93, p. 90759092.

Engdahl, E.R., van der Hilst, R., and Buland, R., 1998, Global teleseismic earthquake location with improved travel-times and procedures for depth determination: Bulletin of the Seismological Society of America, v. 88, p. 722-743.

Evernden, J.F., 1969, Precision of epicenters obtained by small numbers of world-wide stations: Bulletin of the Seismological Society of America, v. 59, p. 1365-1398.

Frohlich, Cliff, 1982, Seismicity of the central Gulf of Mexico: Geology, v. 10, p. 103-106.

Herrin, Eugene (Chairman) and others, 1968, 1968 Tables for P phases, Bulletin Seismological of the Society of America, v. 58, p. 1193-1352.

Kovach, R.L., 1974, Source mechanisms for Wilmington Oil Field, California, subsidence earthquakes, Bulletin of the Seismological Society of America, v. 54, p. 699-711.

McGarr, Arthur, 1984, Scaling of ground motion parameters, state of stress, and focal depth: Journal of Geophysical Research, v. 89, p. 6969-6979.

Minerals Management Service, 2008, MMS Public US Data Viewer, http://oceanenergy.mms.gov/mms_us/, last accessed January 2008. 
Nettles, Meredith, 2006, Teleseismic analysis of two unusual seismic events in the Gulf of Mexico in 2006: 2006 Society for Exploration Geophysicists extended abstracts for special workshop The 10 February 2006, Magnitude 5.2 Gulf of Mexico earthquake: Insights and implications.

Nettles, Meredith, 2007, Analysis of the 10 February 2006 Gulf of Mexico Earthquake from Global and Regional Seismic Data: 2007 Offshore Technology Conference abstract \#19099, http://www.otcnet.org/2007/technical/schedule/documents/otc190991.pdf, last accessed November 2007.

Nunn, J.A., 1985, State of stress in the northern Gulf Coast: Geology, v. 13, p. 429-432.

Ottemöller, Lars, Nielsen, H.H., Atakan, K., Braunmiller, J., and Havskov, J., 2005, The 7 May 2001 induced seismic event in the Ekofisk oil field, North Sea: Journal of Geophysical Research, v. 110, B10301, doi:10.1029/2004JB003374, 15 p.

Peel, F.J., Travis, C.J., and Hossack, J.R., 1995, Genetic structural provinces and salt tectonics of the Cenozoic offshore U.S. Gulf of Mexico; A preliminary analysis, in Jackson, M.P.A., Roberts, D.G., and Snelson, S., eds, Salt tectonics: A global perspective, American Association of Petroleum Geologists Memoir, v. 65, p. 153-175.

Regone, C.J., 1997, Measurement and identification of 3-D coherent noise generated from irregular surface carbonates, in K.J. Marfurt, ed., Carbonate seismology: Society of Exploration Geophysicists, p. 281-305.

Richter, C.F., 1958, Elementary seismology, San Francisco, W.H. Freeman, 768 p.

Rijken, O., and Leverette, S., 2007, Tension leg platform response to earthquake in Gulf of Mexico: Proceedings of the 17th International Offshore and Polar engineering conference, p. 190-193, ISBN 978-1-880653-68-5.

Ross, A.A., and Beaudoin, G., 2006, Field design and operation of a deep water, wide-azimuth node seismic survey: Society of Exploration Geophysicists Technical Program Expanded Abstracts, p. 2920-2924, doi:10.1190/1.2370133.

Stevens, J.L., and Day, S.M., 1985, The physical basis of $\mathrm{m}_{\mathrm{b}}: \mathrm{M}_{\mathrm{s}}$ and variable magnitude methods for earthquake/explosion discrimination: Journal of Geophysical Research, v. 90, p. 3009-3020.

U.S. Geological Survey, 2007, International registry of seismograph stations, http://neic.usgs.gov/neis/station_book/, last accessed October 2007.

U.S. Geological Survey, 2008, Community Internet Intensity Maps, Central U.S. Archives, 2006, http://pasadena.wr.usgs.gov/shake/cus/2006.html, last accessed January 2008. 


\section{References to Follow-up Investigations}

Blum, John, 2010, The $M_{S} 5.3$ Green Canyon (northern Gulf of Mexico) earthquake of 10 February 2006-A landslide source?, chap. 6 of Blum, John, Development of sensors and techniques to assess earthquake hazards and submarine slope stability: San Diego, University of California-San Diego, Ph.D. dissertation, p. 132-171, accessed January 2011 at http://gradworks.umi.com/34/12/3412283.html and http://gradworks.umi.com/3412283.pdf.

Dellinger, Joseph, Blum, John, and Nettles, Meredith, 2009, The 10 February 2006 “Green Canyon" earthquake-A case history of an unusual seismic event: Society of Exploration Geophysicists Expanded Abstracts, v. 28, p. 572-576, http://dx.doi.org/10.1190/1.3255822. 